\title{
DESENVOLVIMENTO DE UM MODELADOR DE MOLDES E DE UM VISUALIZADOR DE ESCOAMENTO DE FLUIDOS
}

\author{
Jaqueline Murakami Kokitsu
}

Orientador: Prof. Dr. Antonio Castelo Filho

Dissertação apresentada ao Instituto de Ciências Matemáticas de São Carlos, Universidade de São Paulo, como parte dos requisitos para a obtenção do Título de Mestre em Ciências - área: Ciências de Computação e Matemática Computacional.

USP - São Carlos

Dezembro de 1996 
Aos meus pais, por tudo o que sou.

Ao Lélio, pelo carinho, compreensão e incentivo.

Ao meu filho Lucas, pela alegria de seu nascimento durante a realização deste trabalho. 


\section{Agradecimentos}

Ao Prof. Dr. Antonio Castelo Filho, pela orientação, ensinamentos, apoio e amizade no transcorrer deste trabalho.

Ao Prof. Dr. Murilo F. Tomé pelas inúmeras dúvidas esclarecidas, sugestões propostas e incentivo.

Aos funcionários da Secretaria e Biblioteca do ICMSC pela atenção dedicada.

Aos colegas do Instituto de Pesquisas Meteorológicas (IPMet-unesp-Bauru) pelo apoio e cooperação.

Ao IPMet pela concessão do afastamento para realização deste trabalho. 


\section{Resumo}

A área de Dinâmica de Fluido Computacional caracteriza-se pelo amplo uso dos recursos da Computação Gráfica com o objetivo de analisar e validar os resultados de suas simulações. Em conexão com o Simulador de Escoamento de Fluidos FREEFLOW, foi desenvolvido um pacote gráfico que oferece facilidades para introdução de dados do domínio e parâmetros do escoamento, bem como possibilita a visualização gráfica dos resultados das simulações realizadas.

\footnotetext{
Abstract

Computational Fluid Dynamics is characterized by the ample use of Computer Graphics in order to analyse and validate results from its simulations. In connection with the FREEFLOW fluid flow code, a graphical package was developed that provides facilities for collecting domain data and flow parameters as well as displaying results of the simulation graphically.
} 


\section{Índice}

Capítulo 1 - Introdução

1.1 Considerações Iniciais. . . . . . . . . . . . . . . . . . . . 1

1.2 Motivação e Objetivos......................... 2

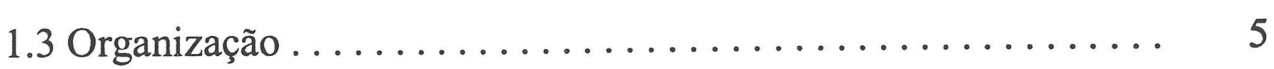

Capítulo 2 - Modelagem Geométrica

2.1 Considerações Iniciais. . . . . . . . . . . . . . . . . . . . 6

2.2 Breve Histórico $\ldots \ldots \ldots \ldots \ldots \ldots \ldots \ldots \ldots \ldots \ldots \ldots \ldots \ldots$

2.3 Elementos da Modelagem Geométrica ................. 9

2.4 Operações de Manipulação da Forma ................... 14

2.5 Transformações Geométricas ....................... 15

2.6 Modelagem 2D . . . . . . . . . . . . . . . . . . . . 16

2.6.1 Instanciamento de Primitivos ................ 16

2.6.2 Interpolação por splines cúbicas . . . . . . . . . . . . . 17

2.6.3 Curvas B-splines.......................... 18

2.6.3.1 Introdução........................ 18

2.6.3.2 Definição........................ 19

2.6.3.3 Propriedades..................... 20

2.6.3.4 Manipuladores de Controle .............. 21

Capítulo 3 - O Simulador de Escoamento de Fluido-FREEFLOW

3.1 Considerações Iniciais. ......................... 26

3.2 Introdução. ............................... 26

3.3 Descrição do Programa FREEFLOW................. 28

3.3.1 Equações Básicas. .......................... 28

3.3.2 Metodologia Empregada...................... 29 
3.3.3 Condições de Contorno.................. 30

3.3.4 Condições de Contorno na Superfície Livre. ......... 31

3.3.5 Partículas Virtuais (Marker Particles) ............. 31

3.3.6 Tipos de Células Empregadas na Malha........... 32

3.3.7 Definição do Domínio e Composição da Malha. ........ 34

3.3.8 As Variáveis da Célula.................. 35

Capítulo 4 - Visualização

4.1 Considerações Iniciais. . . . . . . . . . . . . . . . 36

4.2 Aspectos da Visualização Computacional . . . . . . . . . . 37

4.3 Processamento de Mapas de Contorno. ............... 41

4.3.1 Métodos para Contorno de Funções de Duas Variáveis. . . . . 42

Capítulo 5 - O Modelador de Moldes e o Visualizador de Escoamento de Fluidos

5.1 Considerações Iniciais. . . . . . . . . . . . . . . 49

5.2 X Window, X Toolkit Intrinsics e Motif . . . . . . . . . . 51

$5.2 .1 \times$ Window. ........................ 52

$5.2 .2 \times$ Toolkit Intrinsics. . . . . . . . . . . . . 54

5.2 .3 Motif. . . . . . . . . . . 57

5.3 Aspectos Gerais da Implementação. . . . . . . . . . . 59

5.4 O Modelador de Moldes.................... 62

5.5 A Interface de Entrada de Dados para o Simulador. . . . . . . . 67

5.60 Visualizador de Escoamento de Fluidos............ 70

5.7 Exemplos. . . . . . . . . . . . . 74

Capítulo 6 - Conclusões............................ 82

Bibliografia $\ldots \ldots \ldots \ldots \ldots \ldots \ldots \ldots$ 


\section{Figuras}

2.1 Módulos de um Sistema Gráfico . . . . . . . . . . . . . . . 7

2.2 Varredura Rotacional e Varredura Translacional. ............... 11

2.3 Representação por Decomposição ..................... 12

2.4 Representação CSG . . . . . . . . . . . . . . . . . . . 13

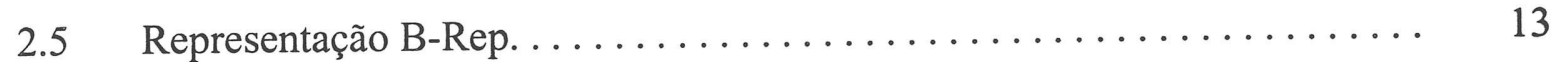

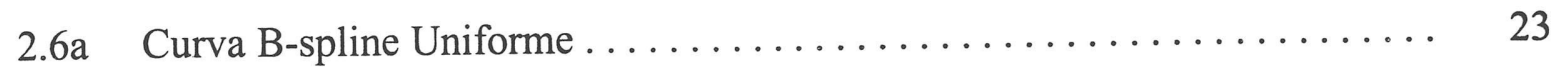

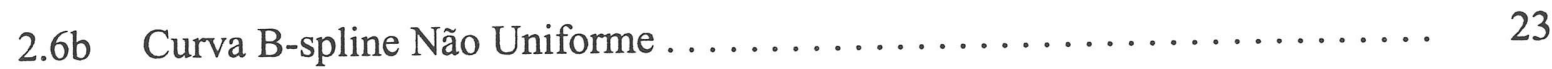

2.7 Efeito da Variação da Ordem em Curvas B-spline ............... 24

2.8 Efeito de Vértices Múltiplos em $\mathrm{B}_{2} \ldots \ldots \ldots \ldots \ldots \ldots \ldots \ldots \ldots \ldots \ldots \ldots$

2.9 Controle Local numa Curva B-spline. . . . . . . . . . . . . . . 25

3.1 Exemplo dos Tipos de Células de uma Malha. ................ 34

3.2 Configuração de uma Célula. . . . . . . . . . . . . . . . . 35

4.1 Subdivisão Empregada no Método de Sibson e Thomson. ............ 44

4.2 Contorno da função $x^{2}+y^{2}-c=0$, para $c=0.1(0.1) 7.6$, usando o algoritmo tradicional com uma grade $16 \times 16 \ldots \ldots \ldots \ldots \ldots \ldots \ldots \ldots$

4.3 Contorno da função $x^{2}+y^{2}-c=0$, para $c=0.1(0.1) 7.6$, usando o algoritmo tradicional com uma grade $64 x 64 \ldots \ldots \ldots \ldots \ldots \ldots \ldots \ldots . \ldots \ldots$

4.4 Algoritmo 1 proposto por Suffern ................... 47

4.5 Contorno da função $x^{2}+y^{2}-c=0$, para $c=0.1$ e 7.6 , usando quadtrees com search_depth $=2$ e plot_depth $=6 \ldots \ldots \ldots \ldots \ldots \ldots \ldots \ldots . \ldots \ldots$

4.6 Contorno da função $x^{2}+y^{2}-c=0$, para $c=0.1$ e 7.6, usando o algoritmo 2 com search_depth $=2 \ldots \ldots \ldots \ldots \ldots \ldots \ldots \ldots \ldots \ldots \ldots \ldots$

5.1 Hierarquia de classes para o conjunto de widgets Motif e Xt ........ 56

5.2 Modelo de interfaceamento entre camadas na construção de uma aplicação. . . 57

5.3 Estrutura de diretórios do sistema Simulador de Escoamento de Fluidos .... 60

5.4 Exemplo da técnica "Rubberbanding" ................... 62

5.5 Exemplo de "Dragging" na movimentação de um objeto . . . . . . . . . . 63

5.6 Exemplo do uso de "handles" para alteração da forma de um objeto . . . . . . . 64 
5.7 Exemplo de molde construído com poli-linhas, arcos de cincunferência, splines e B-splines. . . . . . . . . . . . . . . . . 74

5.8 Exemplo de um molde construído com B-splines e poli-linhas e com a operação "Move Pt" acionada. .............................. 75

5.9 Exemplo de um molde construído com B-splines e poli-linhas após operações de movimentação e adição de pontos . . . . . . . . . . . . . 75

5.10 Janela para carga de um arquivo de molde $\ldots \ldots \ldots \ldots \ldots \ldots \ldots \ldots \ldots$

5.11 Janela para introdução de dados no Modelador no formato do programa

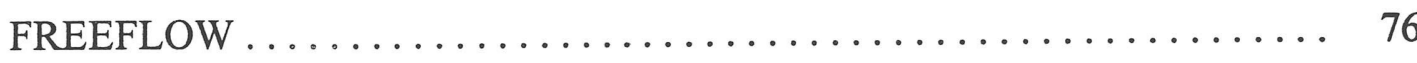

5.12 Exemplo de uma caixa de diálogo de ajuda após a escolha da opção "on context" e clicagem sobre o botão "Move Pt" para movimentação de um

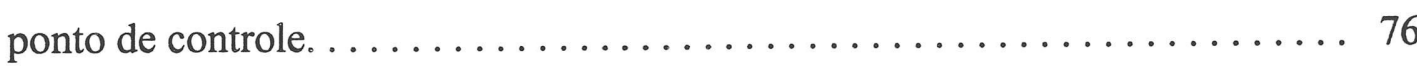

5.13 A interface para entrada de dados do Simulador FREEFLOW. . . . . . . . . 77

5.14 Janela para introdução de informações sobre o inflow do molde selecionado na interface para entrada de dados da simulação. . . . . . . . . . . . 77

5.15 Apresentação de vetores representando a velocidade do fluido. . . . . . . . . 78

5.16 Apresentação do bordo do fluido preenchido com cores distintas. . . . . . . . 78

5.17 Sobreposição dos campos pressão, mostrado com contornos preenchidos e partículas de fluido . ........................... 79

5.18 Sobreposição dos campos partículas e grade de células. . . . . . . . . . . . 79

5.19 Linhas de contorno escolhidas pelo usuário. . . . . . . . . . . . . . . 80

5.20 Janelas para controle da animação. . . . . . . . . . . . . . . 80

5.21 Janela para configurar a apresentação das linhas de contorno. . . . . . . . . 8 81

5.22 Janela para escolha do passo no tempo ou índice de plotagem (IPLOT)...... 81 


\section{Capítulo 1}

\section{Introdução}

\subsection{Considerações Iniciais}

O uso do computador nas diferentes áreas do conhecimento humano está intimamente relacionado com o estudo de modelos. Nesse contexto, o computador funciona como uma ferramenta eficiente, que provê técnicas para sua criação, fornece informações sobre o modelo e oferece formas eficientes para sua representação e observação de seu comportamento. A computação gráfica participa desse processo principalmente nas fases de construção e visualização do modelo.

Outra área que está usufruindo do desenvolvimento da tecnologia da computação gráfica é a visualização científica. A visualização científica tornou-se uma área de grande importância a partir da década de 80 , quando cientistas e engenheiros perceberam a impossibilidade de interpretação da prodigiosa quantidade de dados obtida sem a sintetização dessas informações em alguma forma de representação gráfica. Técnicas de computação gráfica também permitem a visualização dinâmica de fenômenos que variam com o tempo, resultando numa importante ferramenta para processos de simulação. Uma das áreas que vem sentindo os benefícios dos avanços em visualização computacional é a Dinâmica de Fluido, pela possibilidade de visualização e compreensão dos resultados volumosos e complexos de suas simulações. 
A computação gráfica interativa, utilizada em modelagem de objetos e visualização científica, permite uma melhoria sensível na comunicação usuário-computador, aperfeiçoando de forma significativa a habilidade do usuário em construir formas, compreender dados, perceber tendências e visualizar imagens. Ao tornar a comunicação mais eficiente, softwares gráficos interativos também aumentam a produtividade, geram produtos de melhor qualidade e precisão e diminuem custos de análise e projeto.

\subsection{Motivação e Objetivos}

Está sendo desenvolvido no Instituto de Ciências Matemáticas de São Carlos (ICMSC) da Universidade de São Paulo, um sistema computacional para simulação de escoamento de fluidos (FREEFLOW), que possibilita a análise e a observação do comportamento dinâmico de fluidos viscosos incompressíveis.

Simulações de escoamentos de fluidos viscosos são particularmente relevantes no contexto industrial. Esse tipo de escoamento aparece em diversas aplicações industriais, tais como injeção de fluidos em moldes complexos (indústria de fabricação de plásticos), escoamento de metais (indústria siderúrgica), escoamento em cavidade (indústria alimentícia). O interesse de indústrias desta natureza em utilizar o código FREEFLOW para simular escoamentos de fluidos em domínios arbitrários, resultou na necessidade de se desenvolver uma interface amigável para o mesmo e que facilitasse a utilização do simulador FREEFLOW. 
A ausência de uma interface gráfica para a introdução e consistência de dados de entrada para o simulador, bem como ferramentas que possibilitassem uma visualização gráfica eficiente dos resultados da simulação, motivou o desenvolvimento deste trabalho.

O simulador requer a definição de parâmetros que configuram o tipo do escoamento a ser modelado, entre estes podemos citar: a viscosidade, o tipo do modelo, a tolerância para o método do gradiente. Por se tratar de informações bastante específicas da área de dinâmica de fluidos, a introdução desses dados, realizada pelo posicionamento adequado de cada valor de variável em um arquivo ASCII, dava margem a uma grande ocorrência de erros de especificação. Este aspecto resultou, como conseqüência, na proposta de construção de uma interface gráfica para introdução e consistência de dados de entrada para o simulador, bem como acionamento e monitoramento do módulo de simulação de escoamento de fluidos.

O Simulador de Escoamento de Fluidos possui também como dado de entrada, o domínio do fluido, ou seja, o molde dentro do qual o fluido é introduzido. Com base nesta informação é possível apresentar a distribuição do fluido dentro do molde em intervalos regulares de tempo. Dificuldades na descrição do molde, motivou o desenvolvimento de um modelador de moldes utilizando técnicas de modelagem geométrica e outros recursos da computação gráfica interativa.

Outro aspecto de muito interesse é a visualização eficiente das saídas do sistema simulador, resultando na proposta de implementação de um visualizador para o código FREEFLOW.

O objetivo do presente trabalho é, portanto, desenvolver um sistema gráfico interativo de suporte ao simulador de escoamento de fluido. Este sistema conta com técnicas gráficas 
de auxílio à definição e ingestão de dados de entrada para o simulador, bem como facilidades para a visualização de seus resultados.

O Modelador de Moldes dispõe de capacidade de modelagem bidimensional, utilizando-se as técnicas: Instanciamento de Primitivas e Aproximações/Interpolações por splines cúbicas e B-splines. O trabalho desenvolvido estabelece formas eficientes para a construção e manipulação de objetos, sendo possível utilizar esta ferramenta para definir a lâmina 2D que representa uma seção transversal ou um perfil axial de objetos tridimensionais.

O módulo de visualização bidimensional dos resultados da simulação dispõe de técnicas que possibilitam a visualização da forma, propriedade e dinâmica de escoamento do fluido. O fluido pode ser apresentado na forma de partículas, ou pela descrição de seu bordo (preenchido ou não). Mapas de contornos são utilizados para visualizar propriedades do fluido, como pressão, temperatura e velocidade, e vetores representam a direção da velocidade das partículas do fluido. O comportamento do fluido no decorrer do tempo é apresentado através do recurso de animação. 


\subsection{Organização}

No capítulo 2 é apresentada a fundamentação teórica relacionada à modelagem geométrica e apresentação das técnicas empregadas em modelagem bidimensional.

O capítulo 3 é reservado para apresentação do sistema simulador de escoamento de fluido (FREEFLOW).

O capítulo 4 discorre sobre a teoria envolvida no processo de visualização de dados e imagens, com atenção especial às técnicas de definição de contornos a partir de grades de dados.

O capítulo 5 trata aspectos da implementação do Modelador de Moldes e do Visualizador de Escoamento de Fluidos 2D.

O capítulo 6 destaca as contribuições do trabalho desenvolvido, seguidas de sugestões para futuros trabalhos. 


\section{Capítulo 2}

\section{Modelagem Geométrica}

\subsection{Considerações Iniciais}

Entende-se por modelagem a criação, representação e manipulação de objetos no computador. Na modelagem geométrica os objetos modelados obedecem a regras formais da geometria clássica. A modelagem geométrica utiliza e aplica conceitos da geometria, cálculo vetorial, topologia e análise numérica.

Muitas vezes, o objetivo da criação de um modelo no computador é o de se efetuar simulações com o mesmo. Em geral, os problemas a serem simulados envolvem aspectos cinemáticos e dinâmicos. O sistema de modelagem deve, portanto, possuir meios que permitam a visualização do movimento de objetos.

A simulação do ambiente no qual se encontra o modelo também deve levar em conta a troca de energia luminosa entre os objetos da cena, envolvendo aspectos de textura, iluminação e cor dos modelos.

Denomina-se Sistema Gráfico um ambiente de software que envolve produção gráfica e desenvolvimento, onde técnicas de computação gráfica são utilizadas para a realização de simulações com propósitos que vão desde a criação de um realismo fotográfico até a utilização de modelos científicos. Em sistemas de modelagem é importante a possibilidade de realização de operações sobre os objetos modelados, de modo a torná-lo adequado aos 
objetivos desejados. Outra característica desejável é a realização de transformações geométricas que permitam alteração da posição, orientação e tamanho dos objetos modelados. A fig. 2.1 mostra um diagrama de um sistema gráfico com seus vários módulos [Gome90].

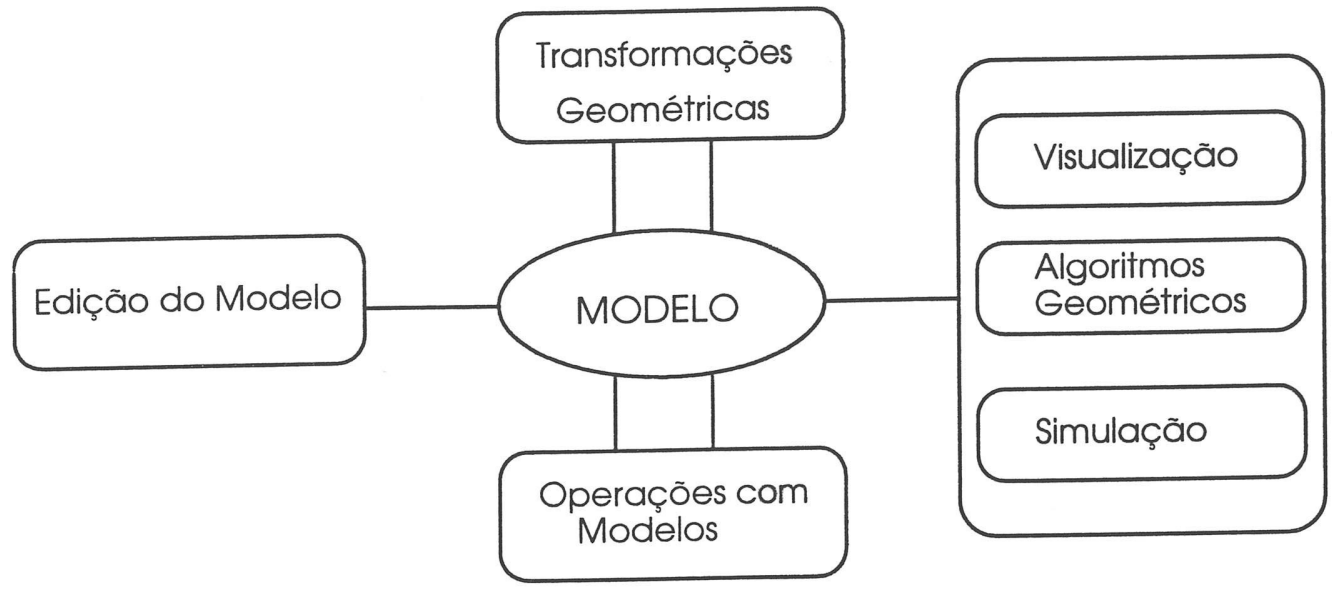

Fig. 2.1 : Módulos de um sistema gráfico

O objetivo deste capítulo é, inicialmente, apresentar um breve histórico evolutivo da área de modelagem geométrica em computação gráfica. Em seguida serão discutidos os principais conceitos da área de modelagem geométrica, sendo dado um enfoque mais geral, englobando inclusive aspectos relativos à modelagem de sólidos. Uma seção especial é dedicada para apresentação das técnicas de modelagem bidimensional. 


\subsection{Breve Histórico}

No início dos anos 60 surgiram trabalhos relacionados à utilização de computadores no projeto e manufatura de produtos industriais, de acordo com os artigos de Coons [Coon63] sobre requisitos de sistemas auxiliados por computador, de Sutherland [Suth63], sobre o uso do "Sketchpad" e de Roberts [Robe63] sobre o problema de remoção de linhas escondidas.

O sistema "Sketchpad", desenvolvido por E. Sutherland, marcou de forma definitiva não apenas o início da computação gráfica interativa, mas também lançou a pedra fundamental para a área de modelagem. O sistema de Sutherland permitia a criação e manipulação de objetos geométricos bidimensionais no computador, usando conceitos de transformações planares e vínculos geométricos.

A partir de então, surgiram os sistemas nos quais as pranchetas eram substituídas pelo computador para a criação das chamadas "plantas baixas" (projeções ortogonais) dos projetos. Estes sistemas, por sua vez, evoluíram para os sistemas de desenho 3D. Tais modelos tornaram-se conhecidos como modelos fio-de-arame ("wireframe")[Fole90]. Uma vantagem deste tipo de representação é que o computador podia gerar desenhos do objeto de qualquer ponto de vista e em qualquer projeção definida.

Problemas como a impossibilidade de obtenção de propriedades físicas do modelo (área, volume, massa, etc) e realização de análises de inferências, além da grande quantidade de objetos inconsistentes e ambíguos gerados através desta técnica, motivaram o desenvolvimento de formalismos matemáticos para definição e representação de modelos no computador. Um trabalho pioneiro nesta direção foi iniciado por Requicha [Requ80] que estabeleceu um conjunto de propriedades necessárias para classificar um objeto como 
sólido válido (manufaturável), incrementando de forma significativa a área de modelagem de sólidos.

\subsection{Elementos da Modelagem Geométrica}

A técnica de modelagem geométrica possibilita a descrição da forma e de outras características geométricas de um objeto, bem como a simulação de processos dinâmicos. Dessa forma, ela é capaz de prover modelos abstratos de objetos ou processos reais, que são economicamente mais convenientes de serem experimentados, e mais facilmente analisados que seus correspondentes reais [Mort85].

De acordo com Requicha [Requ83], o termo Modelagem de Sólidos envolve teorias, técnicas e sistemas para obtenção de representações sólidas com capacidades de cálculo automático de qualquer propriedade geométrica do objeto modelado. A principal importância dos sistemas de modelagem de sólidos é a possibilidade de identificação do interior, exterior e superfície do objeto [Mort85].

Um enfoque mais rigoroso da modelagem de objetos baseia-se em sua subdivisão em três níveis de abstracão [Mänt88]:

- Universo Físico: onde estão os objetos que se deseja modelar;

- Universo Abstrato: que representa uma idealização dos modelos do mundo físico. Nesse universo os objetos tem uma relação com o mundo físico, no entanto, apresenta um nível de abstração que permite sua descrição através de um modelo matemático; 
- Representação: constitue a atribuição de uma estrutura simbólica que descreve o modelo matemático do objeto e é adequada para representação e manipulação no computador.

A visão da modelagem em três níveis de abstração permite a caracterização rigorosa das propriedades desejáveis de métodos de modelagem de objetos através da análise do relacionamento entre entes matemáticos e suas representações no computador.

O desenvolvimento de um sistema de modelagem deve considerar os seguintes aspectos:

- Criação do modelo

- Representação do modelo

- Análise das propriedades do modelo

A criação do modelo baseia-se em métodos geométricos e análise numérica e envolve a utilização de técnicas de modelagem [Gome90]. Essas técnicas servem para criação e descrição de modelos e são dependentes, quase que exclusivamente, da forma de representação utilizada.

A técnica de modelagem por instanciamento de primitivas é uma das formas mais simples de descrição de modelos. Baseia-se no fornecimento prévio das classes de formas básicas e freqüentemente utilizadas, denominadas primitivas. A primitiva é definida por alguns parâmetros específicos, tais como altura, largura e profundidade, no caso de um cubóide, e um objeto abstrato é gerado através da atribuição de valores aos parâmetros. Os próprios parâmetros constituem uma representação para a primitiva [Requ80],[Mänt88].

A varredura (sweeping) constitui uma técnica de modelagem que descreve um objeto abstrato através de uma face planar fechada e uma trajetória não coplanar à face. Os tipos mais comuns de varredura são: a rotacional e a translacional (ver figura 2.2). Na varredura 
rotacional, a face planar é rotacionada em torno de um eixo arbitrário segundo a trajetória escolhida e o modelo equivale ao conjunto de pontos "varridos" durante a rotação. $\mathrm{Na}$ varredura translacional, a face planar é transladada de acordo com a trajetória escolhida [Maga94].

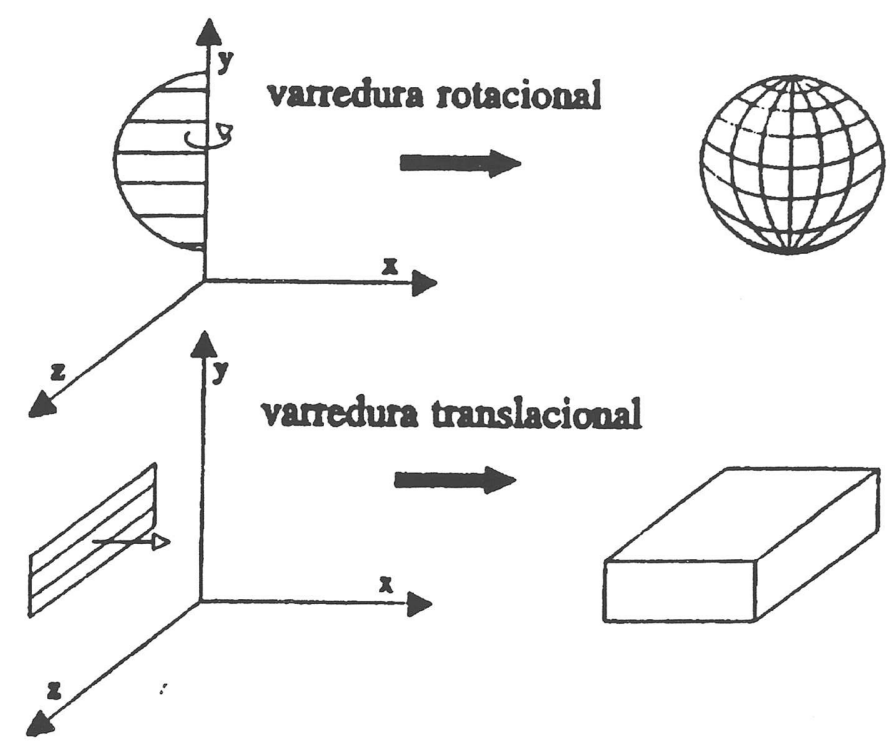

Fig. 2.2 : Varredura Rotacional e Varredura Translacional

Curvas e superfícies paramétricas do tipo B-splines têm recebido atenção crescente como técnica para a criação de objetos geométricos, sendo convenientes para a descrição de objetos abstratos com geometria "escultural". B-splines apresentam diversas vantagens quando utilizadas na modelagem de formas livres, além do alto grau de liberdade e da suavidade das formas obtidas, a sua utilização determina uma descrição alternativa e compacta [Fari90][Bart87]. Além disso, os modelos podem ser visualizados facilmente.

A representação do modelo utiliza-se de técnicas de estruturas de dados e topologia combinatória, de modo a possibilitar o armazenamento do objeto modelado no computador. As principais formas de representação de modelos atualmente utilizadas são: forma de 
representação por decomposição, forma de representação construtiva e forma de representação por fronteira [Requ80], [Mänt88], [Gome90].

Nas representações por decomposição, o modelo é descrito por uma coleção de objetos geométricos mais simples, conhecidos como primitivas, que são combinados entre si através de uma operação denominada colagem. A colagem une as primitivas sem que haja intersecção entre elas. Cada primitiva representa uma parte do modelo. A figura 2.3 exemplifica um modelo representado por decomposição.
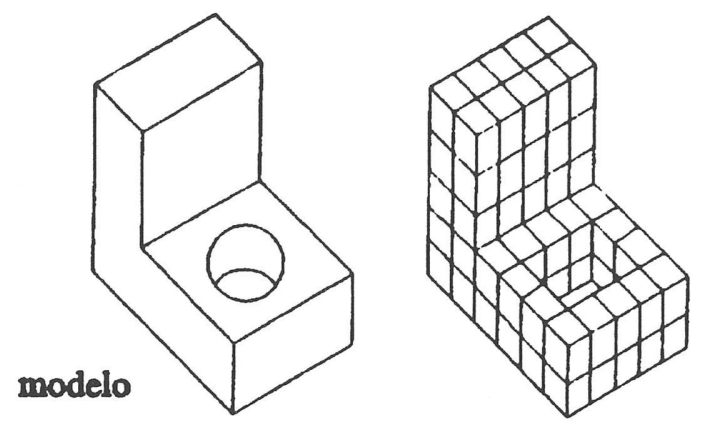

Fig. 2.3 : Representação por Decomposição

Nas representações construtivas, o modelo abstrato é descrito por primitivas geométricas que são transformadas (operações de translação, rotação e escala) e combinadas entre si através de operações booleanas (união, intersecção e diferença).

A forma de representação construtiva mais comum é a Constructive Solid Geometry (CSG). A estrutura de dados associada à representação CSG é uma árvore binária onde os nós folhas correspondem às primitivas e o nós restantes indicam transformações ou operações booleanas [Requ77]. A figura 2.4 ilustra uma representação CSG. 


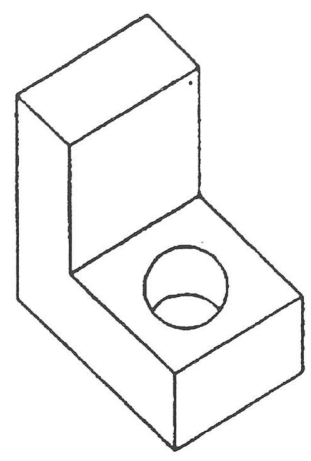

modelo

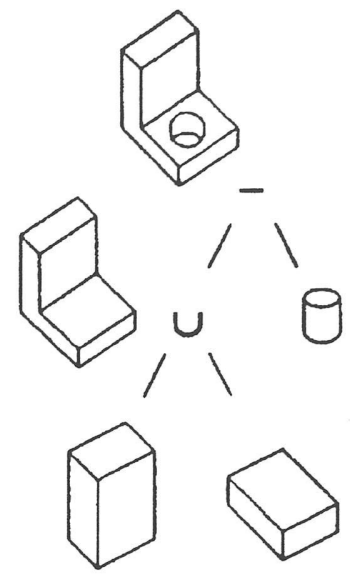

Fig. 2.4 : Representação CSG

$\mathrm{Na}$ representação por fronteira (Boundary Representation - BRep), o modelo abstrato é descrito em termos de sua fronteira, comumente descrita como a união disjunta de superfícies (faces), que são limitadas por curvas (arestas), que por sua vez se interceptam em pontos (vértices) [Mänt88]. Esta hierarquia define a topologia do objeto que, aliada às informações geométricas, fornecem a rigidez do objeto representado. A geometria de um modelo é descrita pelas equações das superfícies sobre as quais estão as faces e equações das curvas sobre as quais estão as arestas e as coordenadas do vértice. A figura 2.5 exemplifica uma representação por fronteira.

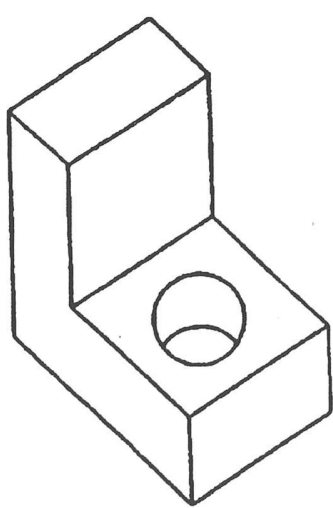

modelo

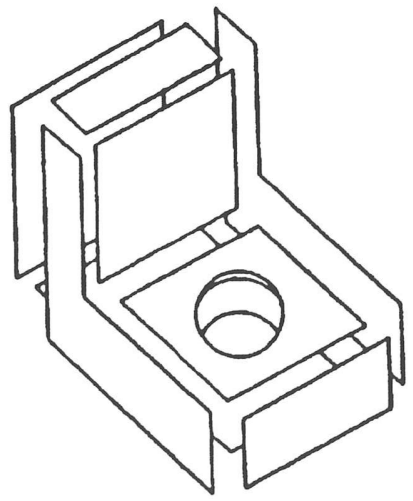

BRep

Fig. 2.5 : Representação B-Rep 
A análise do modelo consiste no estudo das propriedades do objeto modelado. Algoritmos de análise proporcionam respostas a algumas perguntas de natureza geométrica sobre o modelo, com área, volume, curvatura, reação a forças, etc. A especificação de um objeto é geometricamente completa se possui informações suficientes para o cálculo de qualquer propriedade geométrica do objeto modelado, e esta computação depende fortemente do tipo de representação utilizado.

\subsection{Operações de Manipulação da Forma}

Operações que permitam a modificação da forma dos objetos modelados, e a combinação de elementos geométricos primitivos para obtenção de novos objetos são importantes no contexto de criação de modelos. Operações locais permitem pequenas alterações no objeto modelado, de forma simples e eficiente. Entre as técnicas de manipulação local da forma, encontram-se o "Tweaking", para ajuste da geometria das faces, a Chamfradura, que realiza alterações topológicas locais, e o Arredondamento, para suavização de cantos e arestas.

Algumas operações, caracterizadas por atuarem globalmente sobre o objeto modelado, são descritas a seguir.

A Colagem consiste na união de dois elementos primitivos sobre uma aresta/face comum, que poderá ser ou não totalmente coincidente. A colagem é uma forma restrita da 
operação booleana de união, na qual os componentes não podem se interceptar [Fol90,Mort85].

A operação de Corte realiza o particionamento de uma primitiva por um segmento de reta ou curva (no caso bidimensional) ou por um plano (no caso tridimensional), gerando dois novos elementos.

Operações Booleanas são usadas para unir, interseccionar e subtrair objetos, possibilitando a descrição de objetos mais complexos a partir de operações com componentes mais simples.

\subsection{Transformações Geométricas}

As transformações geométricas são utilizadas em modeladores de objetos para definir, calcular e posicionar objetos em uma cena. As transformações geométricas básicas são a translação, a rotação e o escalamento. Transformações adicionais são o espelhamento e a deformação [Fole90]. Existem muitas vantagens em utilizar transformações geométricas. A mais importante delas é a possibilidade de aplicá-las a todos os pontos de um objeto aplicando-as apenas aos seus vértices. Outra vantagem é o uso de formas matriciais, que permite combinar várias transformações antes de aplicá-las ao objeto. 


\subsection{Modelagem 2D}

Num sistema de modelagem 2D, o computador funciona como se fosse uma prancheta de desenho que possibilita a construção e manipulação de objetos através, por exemplo, do instanciamento de primitivas planares, transformações e vínculos geométricos.

Normalmente em sistemas bidimensionais, as técnicas de modelagem para criação do modelo proporcionam também a forma de representação do modelo, ou seja, a estrutura de dados que representa o objeto modelado no computador.

A seguir serão abordadas formas de descrição de objetos através do instanciamento de primitivas, curvas splines e B-splines.

\subsubsection{Instanciamento de Primitivos}

Uma abordagem bastante comum em sistemas de modelagem consiste em fornecer um conjunto finito de objetos geométricos básicos, também denominados primitivos, cujo tamanho, formato, posição e orientação são determinados por um pequeno conjunto de parâmetros especificados pelo usuário. Primitivos planares são descritos sobre um plano xy fictício e encontram-se inicialmente posicionados em relação à origem do sistema de coordenadas definido neste plano fictício. Exemplos de primitivos planares são: o segmento de reta, o arco de circunferência, o círculo, a elipse, o triângulo, o quadrilátero, o polígono. 


\subsubsection{Interpolação por splines cúbicas}

Embora polinômios sejam eficientes instrumentos computacionais, sua utilização na representação de curvas não é usualmente realizada por exigir grau elevado, acarretando em oscilações e instabilidade numérica. Uma solução é dividir a curva em várias partes denominadas segmentos, cada qual com seu respectivo polinômio. A união desses segmentos determina a curva polinomial por partes, e a seqüência de pontos formadas pelas junções dos segmentos denomina-se vetor de nós. A flexibilidade dos polinômios por partes é enriquecida com o uso de polinômios splines, por determinar graus de suavidade global. A interpolação de pontos usando splines cúbicas oferece bons resultados para gerar contornos suaves através da garantia de que o interpolante possui a primeira e a segunda derivadas contínuas no intervalo analisado, ou seja, tanto a inclinação como a curvatura são iguais para os pares de cúbicas que são unidos em cada ponto de interpolação.

Uma spline cúbica pode ser definida como segue [Burd78]:

Dada uma função $f$ definida em $[a, b]$ e um conjunto de pontos, ou nós, $a=x_{0}<x_{1}<\ldots<x_{n}=b$, um interpolante spline cúbico, $S$, para $f$ é uma função que satisfaz as seguintes condições:

a) $S$ é um polinômio cúbico, denotado $S_{j}$, no subintervalo $\left[x_{j}, x_{j+1}\right]$ para cada $j=0,1, \ldots, n-1$

b) $S\left(x_{j}\right)=f\left(x_{j}\right)$ para cada $j=0,1, \ldots, n$;

c) $S_{j+1}\left(x_{j+1}\right)=S_{j}\left(x_{j+1}\right)$ para cada $j=0,1, \ldots, n-2$;

d) $S_{j+1}^{\prime}\left(x_{j+1}\right)=S_{j}^{\prime}\left(x_{j+l}\right)$ para cada $j=0,1, \ldots, n-2$;

e) $S{ }^{\prime \prime}{ }_{j+1}\left(x_{j+1}\right)=S{ }_{j}\left(x_{j+1}\right)$ para cada $j=0,1, \ldots, n-2$;

f) uma das seguintes condições de fronteira seja satisfeita: 
(i) $S^{\prime \prime}\left(x_{0}\right)=S^{\prime \prime}\left(x_{n}\right)=0$

(ii) $S^{\prime}\left(x_{0}\right)=f^{\prime}\left(x_{0}\right)$ e $S^{\prime}\left(x_{n}\right)=f^{\prime}\left(x_{n}\right)$

\subsubsection{Curvas B-splines}

Muitos objetos do mundo real possuem formas curvas sem classificação padrão, dificeis de serem criadas através dos primitivos acima citados. Uma abordagem bastante interessante é o uso de curvas polinomiais "de forma livre". O uso de curvas B-spline é bastante difundido em modelagem de objetos devido ao seu grande poder descritivo provido por suas propriedades .

\subsubsection{Introdução}

A moderna teoria da aproximação spline iniciou em 1946 com Schoenberg [Shoen46], que utilizou B-splines para suavizar dados estatísticos. A definição recursiva utilizada para cálculos numéricos foi o próximo passo importante no desenvolvimento desta teoria, sendo independentemente descoberta por [Cox71] e por [DeBo72]. Gordon e Riesenfeld [Gord74], em 1974, utilizaram a formulação recursiva no contexto de curvas Bspline paramétricas, e também mostraram que a curva B-spline é uma poderosa generalização da curva Bézier.

Uma curva gerada pela utilização de vértices de um polígono de controle é dependente de algum esquema de interpolação ou aproximação que estabelece a relação entre a curva e o polígono. Este esquema é obtido pela escolha de uma função base. A função base B-spline possui característica não global. Este comportamento não global se 
deve ao fato de que cada vértice está associado a uma única função base. Conseqüentemente, cada vértice afeta a forma da curva somente ao longo de um intervalo onde sua função base associada é diferente de zero. A base B-spline também permite que a ordem da função base e portanto, o grau da curva resultante, seja alterado sem mudança no número de vértices do polígono. As definições descritas a seguir foram baseadas em [Roge89].

\subsubsection{Definição}

A equação que expressa uma curva B-spline definida parametricamente em função do parâmetro t é dada por:

$$
P(t)=\sum_{i=1}^{n+1} B_{i} N_{i, k}(t) \quad \text { tmin } \leq t \leq t \max , \quad 2 \leq k \leq n+1
$$

onde

$B_{i}$ são os vértices do polígono de controle (pontos de controle)

$n+1$ é o número de pontos de controle

$N_{i, k}$ são as funções base normalizadas

$\mathrm{k}$ é a ordem da curva B-spline de grau k-1

$t_{\min }, \ldots t_{\max }$ é a seqüência (vetor) de nós

Para a $i$-ésima função base B-spline normalizada de ordem $k$, as funções base são definidas pela fórmula recursiva de Cox-de Boor:

$$
N_{i, l}=\left\{\begin{array}{lr}
1 & \text { se } t_{i} \leq t \leq t_{i}+1 \\
0 & \text { caso contrá ric }
\end{array}\right.
$$




$$
N_{i, k}=\frac{\left(t-t_{i}\right) N_{i, k-1}(t)}{t_{i+k-1}-t_{i}}+\frac{\left(t_{i+k}-t\right) N_{i+1, k-1}(t)}{t_{i+k}-t_{i+1}}
$$

\subsubsection{Propriedades}

Os B-splines normalizados, $N_{i, k}$, são polinômios por partes de grau k-1 definidos sobre os nós $t_{\min }<t_{\min +1}<\ldots<t_{\max -1}>t_{\max }$ e possuem as seguintes propriedades [DeBo72]:

- A soma das funções base B-splines para quaisquer valores de parâmetros $t$ podem ser mostradas como segue (Partição da Unidade):

$$
\sum_{i=1}^{n+1} N_{i, k}(t) \equiv 1
$$

Esta propriedade assegura que qualquer transformação afim pode ser aplicada na curva pela aplicação da mesma sobre os vértices do polígono, ou seja, a curva é transformada pela alteração dos vértices do polígono.

- Cada função base é não negativa para todos os valores de parâmetro, ou seja, $N_{i, k} \geq 0$ (Positividade). Dessa forma indicando que curva está localizada no fecho convexo de seu polígono de controle. Logo, todos os pontos sobre uma curva Bspline estarão dentro da união de todos os fechos convexos formados pelos vértices de seu polígono de controle.

- Exceto para $k=1$ cada função base possui precisamente um valor máximo. 
- O controle da curva é local : $N_{i, k}(t)=0$ se $t \notin\left[x_{i}, x_{i+1}\right]$.

Cada ponto de controle está associado a uma única função base. Cada um desses pontos afeta a forma da curva somente ao redor de um intervalo de valores onde sua função base não é igual a zero.

- $N_{i, k}(t)$ é (k-1) vezes continuamente diferenciável.

- A ordem máxima da curva B-spline é igual ao número de vértices do polígono de controle.

- A curva exibe a propriedade da variação diminuinte, logo, ela não oscila em torno de uma linha reta com mais freqüência que seu polígono de controle.

\subsubsection{Manipuladores de Controle}

A flexibilidade das curvas B-splines é obtida pela possibilidade de uso de diferentes tipos de manipuladores de controle que influenciam a forma da curva:

- O tipo do vetor de nós;

- A ordem $k$ da função base;

- O número e a posição dos vértices do polígono de controle;

- O uso de vértices múltiplos;

- O uso de valores de nós múltiplos. 
A seguir são apresentados alguns exemplos de modificação na forma da curva Bspline através do uso de manipuladores de controle.

A escolha do vetor de nós influi sobre as funções base $N_{i, k}(t)$, como mostrado pela equação (2-2). Três tipos de vetores podem ser usados: uniforme, uniforme aberto (ou aberto) e não uniforme.

Em um vetor uniforme, valores individuais de nós estão regularmente espaçados. Dessa forma, cada função base é uma translação da outra. Exemplos são:

\section{$\left[\begin{array}{lllll}0 & 1 & 2 & 3 & 4\end{array}\right]$}

$\left[\begin{array}{lllll}0 & 0.25 & 0.5 & 0.75 & 1.0\end{array}\right]$

Um vetor de nós uniforme e aberto possui valores de nós múltiplos em seu extremo e igual a ordem $k$ da função base B-spline. Valores de nós internos estão uniformemente espaçados. Alguns exemplos usando incrementos inteiros:

$$
\begin{aligned}
& \mathrm{k}=2\left[\begin{array}{lllllll}
0 & 0 & 1 & 2 & 3 & 4 & 4
\end{array}\right] \\
& \mathrm{k}=3\left[\begin{array}{llllllll}
0 & 0 & 0 & 1 & 2 & 3 & 3 & 3
\end{array}\right]
\end{aligned}
$$

Vetores de nós não uniformes podem possuir nós irregularmente espaçados, bem como nós internos múltiplos. Alguns exemplos:

$\left[\begin{array}{llllllll}0 & 0 & 0 & 1 & 1 & 2 & 2 & 2\end{array}\right]$

$\left[\begin{array}{llllll}0 & 1 & 2 & 2 & 3 & 4\end{array}\right]$

A fig. 2.6 apresenta duas curvas B-splines: uma uniforme (a) e outra não uniforme (b). 


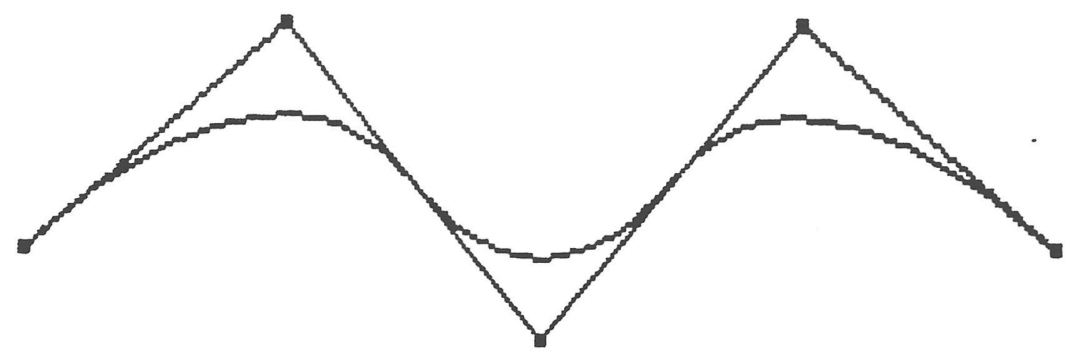

Fig. 2.6a: Curva B-spline uniforme

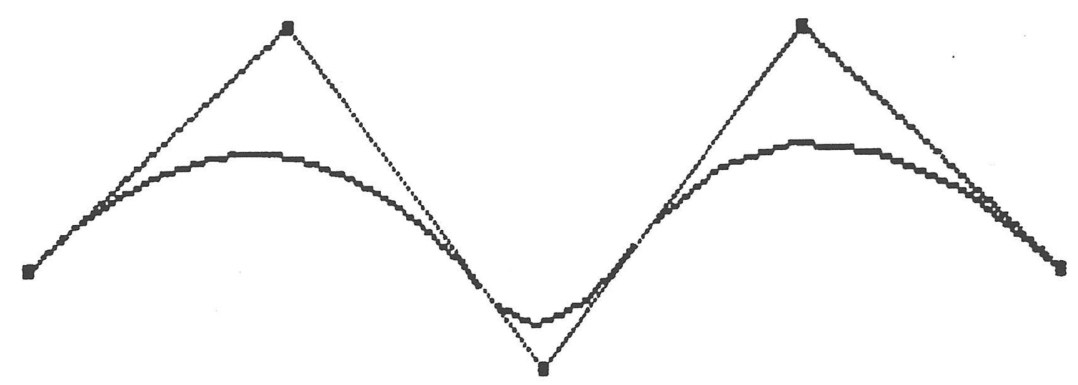

Fig. 2.6b: Curva B-spline não uniforme

A fig. 2.7 mostra três curvas B-splines abertas cada qual possuindo uma ordem diferente, mas definidas pelos mesmos quatro vértices do polígono. Percebe-se que quanto maior a ordem da curva, mais suave é a curva resultante. 


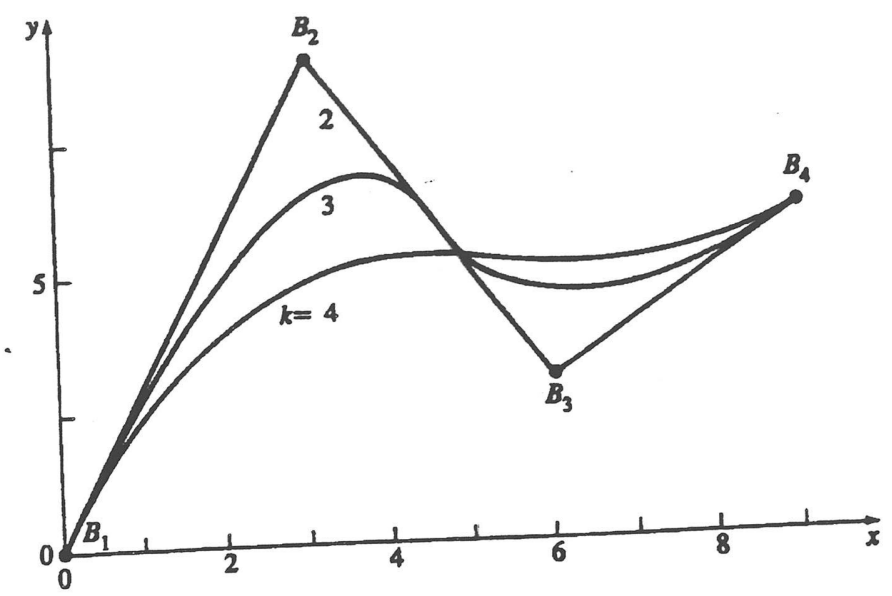

Fig. 2.7: Efeito da variação da ordem em curvas B-splines.

A fig. 2.8 ilustra o efeito de múltiplos vértices coincidentes sobre o polígono de controle. A curva intermediária é definida por cinco vértices com dois vértices coincidentes em $B_{2}$, ou seja, ela é definida pelos vértices $B_{1}, B_{2}, B_{2}, B_{3}$ e $B_{4}$.

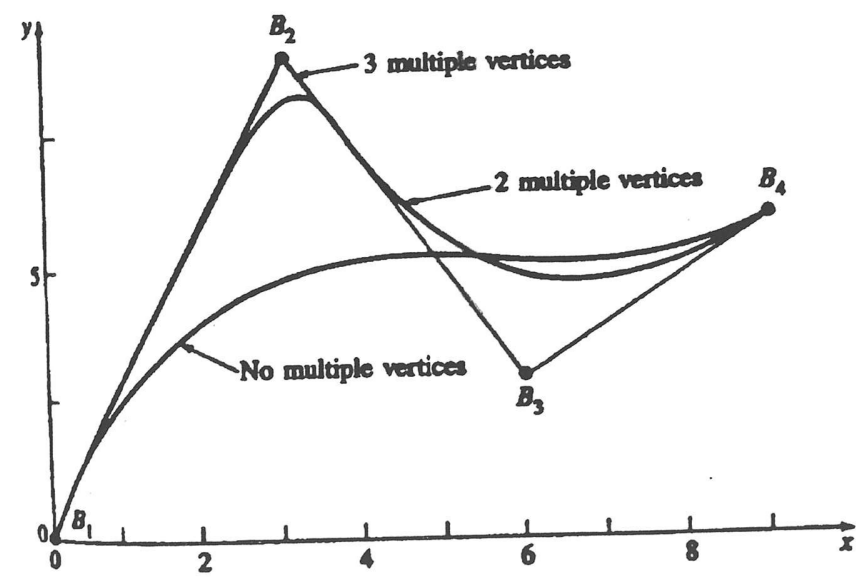

Fig. 2.8: Efeito de vértices múltiplos em $\mathrm{B}_{2}$

O efeito do controle local pode ser observado através da fig. 2.9, que mostra três curvas B-splines obtidas pela movimentação do vértice $\mathrm{B}_{5}$ para as posições $\mathrm{B}_{5}$ ' e $\mathrm{B}_{5}$ '” 
Percebe-se que a movimentação do vértice afeta a curva somente ao redor de uma região limitada.

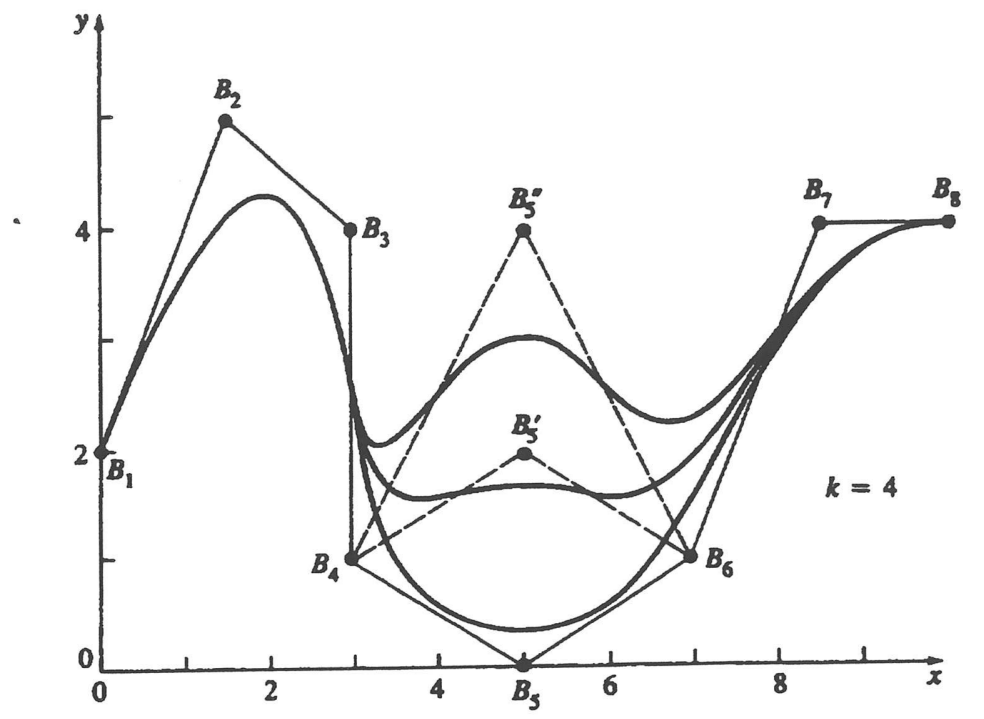

Fig. 2.9: Controle local numa curva B-spline 


\section{Capítulo 3}

\section{O Simulador de Escoamento de Fluido -FREEFLOW}

\subsection{Considerações Iniciais}

Um aspecto de fundamental importância no desenvolvimento de um sistema gráfico interativo, é o conhecimento preciso e detalhado da aplicação que está sendo executada sob o mesmo. Neste capítulo consta o material necessário para a compreensão dos aspectos técnicos envolvidos no processo de simulação do FREEFLOW.

\subsection{Introdução}

FREEFLOW consiste de um conjunto de programas baseado no método GENSMAC [Tome94] cuja finalidade é resolver problemas de escoamento transientes de fluidos (Newtonianos e não-Newtonianos) incompressíveis com superfícies livres. A técnica empregada por FREEFLOW tem suas origens no método SMAC (Simplified-Marker-andCell) que foi desenvolvido em Los Alamos por Harlow e Amsden [Harl71] em meados dos anos 70. SMAC é uma técnica numérica para a investigação da dinâmica de escoamentos de fluidos viscosos incompressíveis que utiliza métodos de diferenças finitas numa malha diferenciada ("staggered grid"). Trata-se de uma técnica que utiliza as variáveis primitivas, pressão e velocidade, e possui particular aplicação na modelagem de escoamentos de 
fluidos com superfícies livres. Uma característica de SMAC é o uso de partículas virtuais (chamadas "marker-particles") cujas coordenadas são armazenadas e que movem de uma célula para outra de acordo com os valores mais recentes da velocidade do fluido a cada instante do tempo. Dessa forma, células contendo partículas indicam a presença do fluido nestas células, o que então permite a visualização da superfície livre do fluido. Outra característica do método é a divisão do ciclo de cálculo em duas partes: uma consistindo no cálculo de um campo de velocidade intermediário e outra para o cálculo da pressão. Esta característica foi a principal motivação para o desenvolvimento de FREEFLOW. Várias modificações no método SMAC foram necessárias para possibilitar o tratamento de escoamentos com superfícies livres em domínios arbitrários, entre os quais citamos: inclusão de uma técnica para tratar de domínios não retangulares, implementação do método gradiente conjugado para a solução da equação de Poisson, revisão das condições de contorno na superfície livre, etc. Estas modificações resultaram no desenvolvimento de um método, denominado GENSMAC, que serviu de base para a implementação de FREEFLOW. Uma descrição completa da metodologia pode ser encontrada em Tome e McKee [Tome91].

Uma implementação recente consiste no uso de técnicas de diferenças finitas para resolver escoamentos axisimétricos com fronteira livre baseado no método SMAC [Tome96a]. A metodologia empregada é uma extensão daquela utilizada no código de FREEFLOW.

Uma outra extensão do código FREEFLOW para o caso tridimensional está em desenvolvimento pelo grupo de análise numérica do ICMSC[Tome96b]. 


\subsection{Descrição do Programa FREEFLOW}

O programa FREEFLOW resolve as equações de Navier-Stokes em duas dimensões para um fluido incompressível. A metodologia empregada é baseada no método SMAC para resolver escoamentos transientes com superfícies livres nas variáveis primitivas velocidade e pressão. FREEFLOW é especialmente desenvolvido de maneira que possa tratar de escoamentos com superfícies livres num domínio arbitrário com condições de fronteira do tipo "free-slip" e "no-slip". Escoamentos com várias aberturas para entrada ("inflows") e saída ( "outflows") de fluidos podem ser tratados e vários obstáculos internos podem ser especificados.

\subsubsection{Equações Básicas}

As equações básicas são as equações de Navier-Stokes juntamente com a equação de conservação de massa. Na forma adimensional são dadas por:

$$
\begin{aligned}
& \frac{\partial u}{\partial t}+\frac{\partial u^{2}}{\partial x}+\frac{\partial u v}{\partial y}=-\frac{\partial p}{\partial x}+\left(\frac{1}{\operatorname{Re}}\right) \frac{\partial}{\partial y}\left(\frac{\partial u}{\partial y}-\frac{\partial v}{\partial x}\right)+\frac{1}{F_{r}^{2}} g_{x} \\
& \frac{\partial v}{\partial t}+\frac{\partial u v}{\partial x}+\frac{\partial v^{2}}{\partial y}=-\frac{\partial p}{\partial y}-\left(\frac{1}{\operatorname{Re}}\right) \frac{\partial}{\partial x}\left(\frac{\partial u}{\partial y}-\frac{\partial v}{\partial x}\right)+\frac{1}{F_{r}^{2}} g_{y} \\
& \frac{\partial u}{\partial x}+\frac{\partial v}{\partial y}=0
\end{aligned}
$$


onde $\operatorname{Re}=U L / v$ e $F r=U / \sqrt{L g}$ são o número de Reynolds e número de Froude, respectivamente. $U$ e $L$ são os fatores de adimensionamento para a velocidade e comprimento, $v$ é a viscosidade cinemática, $g$ é a constante gravitacional com $\mathbf{g}=(g x, g y)^{T}$ o campo gravitacional unitário. $\mathbf{u}=(u, v)^{T}$ são as componentes adimensionais da velocidade e $p$ é a pressão adimensional por unidade de densidade.

\subsubsection{Metodologia empregada}

Suponhamos que num dado instante de tempo, digamos $t_{o}$, o campo da velocidade $\mathbf{u}\left(\mathbf{x}, \mathrm{t}_{\mathrm{o}}\right)$ seja conhecido e sejam dadas condições de contorno para a velocidade e pressão. Então o campo de velocidade $\mathbf{u}(\mathbf{x}, \mathrm{t})$, em $t=t_{o}+\delta t$ é calculado como segue:

1. Seja $\tilde{\mathrm{p}}(\boldsymbol{x}, \mathrm{t} 0)$ um campo de pressão satisfazendo a condição de contorno para a pressão na superfície livre.

2. Calcule o campo de velocidade intermediário $\tilde{\boldsymbol{u}}(\boldsymbol{x}, \mathrm{t})$ pela discretização explícita das seguintes equações

$$
\begin{aligned}
& \frac{\partial \tilde{u}}{\partial t}=\left[-\frac{\partial u^{2}}{\partial x}-\frac{\partial u v}{\partial y}-\frac{\partial \tilde{p}}{\partial x}+\left(\frac{1}{\operatorname{Re}}\right) \frac{\partial}{\partial y}\left(\frac{\partial u}{\partial y}-\frac{\partial v}{\partial x}\right)+\frac{1}{F_{r}^{2}} g_{x}\right]_{t=t_{0}} \\
& \frac{\partial \tilde{v}}{\partial t}=\left[-\frac{\partial u v}{\partial x}-\frac{\partial v^{2}}{\partial y}-\frac{\partial \tilde{p}}{\partial y}-\left(\frac{1}{\operatorname{Re}}\right) \frac{\partial}{\partial x}\left(\frac{\partial u}{\partial y}-\frac{\partial v}{\partial x}\right)+\frac{1}{F_{r}^{2}} g_{y}\right]_{t=t_{0}}
\end{aligned}
$$


onde $\tilde{\boldsymbol{u}}(\boldsymbol{x}, \mathrm{t} 0)=(\mathrm{u}, \mathrm{v})^{\mathrm{T}}$, usando as condições de contorno para $\boldsymbol{u}\left(\boldsymbol{x}, t_{0}\right)$. Pode-se mostrar que $\tilde{\boldsymbol{u}}(\boldsymbol{x}, \mathrm{t})$ contém a vorticidade correta em $t=t_{o}+\delta t$. Porém, $\tilde{\boldsymbol{u}}(\boldsymbol{x}, \mathrm{t})$ não satisfaz $\nabla \cdot \tilde{u}(x, t)=0$.

Seja agora $\bar{u}(x, t)=\tilde{u}(x, t)-\nabla \psi(x, t)$,

com

$$
\nabla^{2} \psi(x, \mathrm{t})=\nabla \cdot \tilde{\boldsymbol{u}}(\boldsymbol{x}, \mathrm{t})
$$

Portanto, $\overline{\boldsymbol{u}}(\boldsymbol{x}, t)$ agora satisfaz

$$
\nabla \cdot \bar{u}(x, t)=0
$$

e a vorticidade permanece inalterada. O campo de velocidade $\bar{u}(x, t)$ é então identificado como $\mathbf{u}(\mathbf{x}, \mathrm{t})$.

3. Resolva a equação de Poisson

$$
\nabla^{2} \psi(x, t)=\nabla \cdot \tilde{u}(x, t)
$$

4. Calcule a velocidade

$$
u(x, t)=\tilde{u}(x, t)-\nabla \psi(x, t)
$$

5. Calcule a pressão

$$
\mathrm{p}(\boldsymbol{x}, \mathrm{t})=\tilde{\mathrm{p}}(\boldsymbol{x}, \mathrm{t})+\frac{\psi(x, \mathrm{t})}{\delta \mathrm{t}}
$$

\subsubsection{Condições de Contorno}

As condições de contorno para a velocidade podem ser de vários tipos: "no-slip", "free-slip", "prescribed inflow", "prescribed and continuative outflow". Exceto para a condição "no-slip", a aplicação dessas condições de contorno são semelhantes à maneira 
adotada pelo método SMAC [Harl71]. Para uma discussão detalhada ver Tome [Tome91]. No contorno da malha, a condição de contorno apropriada para a equação de Poisson é dada por $\frac{\partial \psi}{\partial \mathrm{n}}=0$

\subsubsection{Condições de Contorno na Superfície Livre}

As condições de contorno na superfície livre do fluido assumem que as forças normal e tangencial à superfície devem ser nulas. $\mathrm{Na}$ forma diferencial, podem ser escritas como (ver Hirt e Shannon[Hirt69]):

$$
\begin{aligned}
& p-(2 / \operatorname{Re})\left[n_{x}^{2} \frac{\partial u}{\partial x}+n_{x} n_{y}\left(\frac{\partial u}{\partial y}+\frac{\partial v}{\partial x}\right)+n_{y}^{2} \frac{\partial v}{\partial y}\right]=0 \\
& (1 / \operatorname{Re})\left[2 n_{x} m_{x} \frac{\partial u}{\partial x}+\left(n_{x} m_{y}+n_{y} m_{x}\right)\left(\frac{\partial u}{\partial y}+\frac{\partial v}{\partial x}\right)+2 n_{y} m_{y} \frac{\partial v}{\partial y}\right]=0
\end{aligned}
$$

respectivamente, onde $\mathrm{n}$ e $\mathrm{m}$ são os vetores normal e tangencial à superfíce respectivamente. Estas condições são impostas fazendo-se aproximações por diferenças finitas.

\subsubsection{Partículas Virtuais (Marker-Particles)}

Partículas virtuais são usadas para representar o fluido. A principal tarefa dessas partículas é fornecer a posição da superfície em movimento de maneira que as condições de contorno possam ser aplicadas de uma maneira eficaz. No fim de cada ciclo, as posições 
dessas partículas são recalculadas, o que fornece, então, a dinâmica do fluido em movimento.

As novas coordenadas das partículas são obtidas resolvendo-se a seguinte equação:

$$
\frac{d x}{d t}=u \quad \text { e } \quad \frac{d y}{d t}=v
$$

pelo método de Euler. Logo, toda vez que o campo de velocidade é recalculado, as partículas são movidas de acordo com :

$$
\begin{aligned}
& x_{p}^{n+1}=x_{p}^{n}+u_{p} \delta t^{n+1} \\
& y_{p}^{n+1}=y_{p}^{n}+v_{p} \delta t^{n+1}
\end{aligned}
$$

onde $\left(x_{p}^{n}, y_{p}^{n}\right)$ é a atual posição da partícula, $\delta t^{n+1}$ é o atual passo empregado e $\left(x_{p}^{n+1}, y_{p}^{n+1}\right)$ a nova posição da partícula.

As velocidades $u_{p}$ e $v_{p}$ são obtidas através de uma aproximação bilinear usando as 4 velocidades mais próximas de $u$ e $v$.

\subsubsection{Tipos de Células Empregadas na Malha}

Como o escoamento não é estacionário, um esquema especial para identificar o fluido (e também a superfície livre) é empregado. Isto é obtido definindo-se vários tipos de céludas na malha. Os tipos de células adotados por FREEFLOW são:

1. Células vazias (E) - são células que não possuem fluido. 
2. Células cheias (F) - são células que contém fluido e não possuem lado adjacente com as células vazias (E). Essas células são tratadas como cheias de fluido.

3. Células de superfície (S) - são células que contém partículas mas possuem pelo menos um lado adjacente com células vazias (E). Essas células são tratadas como células contendo a superfície livre do fluido e através delas obtém-se a posição e orientação da superfície em movimento.

4. Células de contorno (B) - são células que identificam o contorno do domínio de maneira que as condições de contorno possam ser aplicadas. Elas são fixas.

5. Células de "outflow" $(O)$ - são células que especificam a posição de um "outflow boundary". Toda vez que uma partículas entra nessas células, ela é destruída.

Logo, durante a execução de um certo problema, uma célula do tipo F pode tornar-se $\mathrm{S}$ e então E, e vice-versa. A figura 3.1 ilustra esses tipos de células para uma certa configuração do fluido juntamente com o domínio. 


\begin{tabular}{|c|c|c|c|c|c|c|c|c|c|c|c|c|c|c|c|c|c|}
\hline B & B & B & B & B & B & B & B & B & B & B & B & B & B & B & B & & B \\
\hline B & B & $\mathbf{E}$ & $\mathbf{E}$ & $\mathbf{E}$ & $\mathbf{E}$ & $\mathbf{E}$ & $\overline{\mathbf{E}}$ & $\mathbf{E}$ & $\mathbf{E}$ & $\mathbf{E}$ & $\bar{E}$ & $\mathbf{E}$ & $\mathbf{E}$ & $\mathbf{E}$ & $\mathbf{E}$ & B & $\overline{\mathbf{B}}$ \\
\hline$\overline{\mathbf{B}}$ & $\mathbf{E}$ & $\mathbf{E}$ & $\mathbf{E}$ & $\mathbf{E}$ & $\mathbf{E}$ & $\mathbf{E}$ & $\mathbf{E}$ & $\mathbf{E}$ & $\mathbf{E}$ & $\mathbf{E}$ & $\mathbf{E}$ & $\mathbf{E}$ & $\mathbf{E}$ & $\mathbf{E}$ & $\mathbf{E}$ & $\mathbf{E}$ & B \\
\hline B & S & $S$ & $\mathbf{E}$ & $\mathbf{E}$ & $\mathbf{E}$ & $\mathbf{E}$ & $\mathbf{E}$ & $\mathbf{E}$ & $\mathbf{E}$ & $\mathbf{E}$ & E & $\mathbf{E}$ & $\mathbf{E}$ & E & $\mathbf{E}$ & $\mathbf{E}$ & B \\
\hline $\bar{B}$ & $\overline{\mathbf{F}}$ & $\mathbf{F}$ & $\bar{S}$ & $S$ & $\mathbf{E}$ & $\mathbf{E}$ & $\mathbf{E}$ & $\mathbf{E}$ & $\mathbf{E}$ & $\mathbf{E}$ & E & $\mathbf{E}$ & $\mathbf{E}$ & $\mathbf{E}$ & $\mathbf{E}$ & $\mathbf{E}$ & $\mathbf{B}$ \\
\hline B & $\mathbf{F}$ & $\mathbf{F}$ & $\mathbf{F}$ & $\mathbf{F}$ & $S$ & $\bar{S}$ & $S$ & $\mathbf{E}$ & $\mathbf{E}$ & $\mathbf{E}$ & E & $\mathbf{E}$ & $\mathbf{E}$ & $\mathbf{E}$ & $\mathbf{E}$ & $\mathbf{E}$ & $\mathbf{B}$ \\
\hline $\mathbf{B}$ & $\mathbf{F}$ & $\mathbf{F}$ & $\mathbf{F}$ & $\mathbf{F}$ & $\bar{F}$ & $\mathbf{F}$ & $\mathbf{F}$ & $S$ & $\mathbf{E}$ & $\mathbf{E}$ & $\mathbf{E}$ & $\mathbf{E}$ & $\mathbf{E}$ & $\mathbf{E}$ & $\mathbf{E}$ & $\mathbf{E}$ & B \\
\hline B & $\mathbf{F}$ & $\mathbf{F}$ & $\mathbf{F}$ & $\mathbf{F}$ & $\mathbf{F}$ & $\mathbf{F}$ & $\mathbf{F}$ & $\mathbf{F}$ & $S$ & S & $\mathbf{E}$ & $\mathbf{E}$ & $\mathbf{E}$ & $\mathbf{E}$ & $\mathbf{E}$ & $\mathbf{E}$ & $\mathbf{B}$ \\
\hline B & $\mathbf{F}$ & $\mathbf{F}$ & $\mathbf{F}$ & $\mathbf{F}$ & $\bar{F}$ & $\mathbf{F}$ & $\mathbf{F}$ & $\mathbf{F}$ & $\mathbf{F}$ & $\mathbf{F}$ & $S$ & $\mathbf{E}$ & \begin{tabular}{|l|}
$\mathbf{E}$ \\
\end{tabular} & $\mathbf{E}$ & $\mathbf{E}$ & $\mathbf{E}$ & $\bar{B}$ \\
\hline $\bar{B}$ & $\mathbf{F}$ & $\mathbf{F}$ & $\mathbf{F}$ & $\mathbf{F}$ & $\mathbf{F}$ & B & $\bar{B}$ & $\bar{B}$ & B & $\mathbf{B}$ & B & $\mathbf{E}$ & \begin{tabular}{|l|}
$\mathbf{E}$ \\
\end{tabular} & E & $\mathbf{E}$ & $\mathbf{E}$ & $\bar{B}$ \\
\hline $\bar{B}$ & $B$ & $\mathbf{F}$ & $\mathbf{F}$ & $\mathbf{F}$ & $\bar{F}$ & $B$ & B & B & B & B & $\$$ & $\mathbf{E}$ & $\mathbf{E}$ & E & $\mathbf{E}$ & B & B \\
\hline$\overline{\mathbf{B}}$ & B & B & B & B & B & B & B & B & B & B & B & B & B & B & B & B & $\mathbf{B}$ \\
\hline
\end{tabular}

Fig. 3.1: Exemplo dos tipos de células de uma malha.

\subsubsection{Definição do Domínio e Composição da Malha}

O domínio de escoamento do fluido pode ser qualquer região conexa do plano. Sua definição é composta de uma matriz denominada "points(n,4)", onde cada linha dessa matriz especifica um segmento do domínio. Logo, o domínio total é composto pela união dos segmentos dessa matriz. Para cada linha da matriz "points" corresponde uma linha de uma matriz chamada "types(n,3)" onde consta a especificação do tipo do segmento, concavidade do segmento e um flag para o próximo segmento. Por exemplo, points $(1,1)$, points( $(1,2)$, points $(1,3)$ e points $(1,4)$ correspondem às coordenadas do primeiro segmento, enquanto que types $(1,1)$, types $(1,2)$ e types $(1,3)$ fornecem as informações sobre o tipo do segmento, tipo da concavidade e o flag para o próximo segmento.

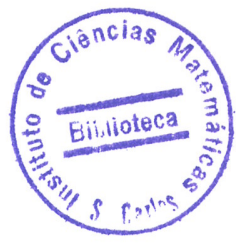




\subsubsection{As Variáveis da Célula}

As principais variáveis da célula da malha são: as duas componentes da velocidade ( $u$ e v), a pseudopressão (p), a divergência de velocidade (D), e a função potencial ( $\psi$ ). Uma célula típica é apresentada na figura 3.2. As velocidades na direção radial são centralizadas nas arestas esquerda e direita da célula e as velocidades axiais nas arestas superior e inferior. As variáveis p, D e $\psi$ estão definidas no centro da célula.

Célula $(i, j)$

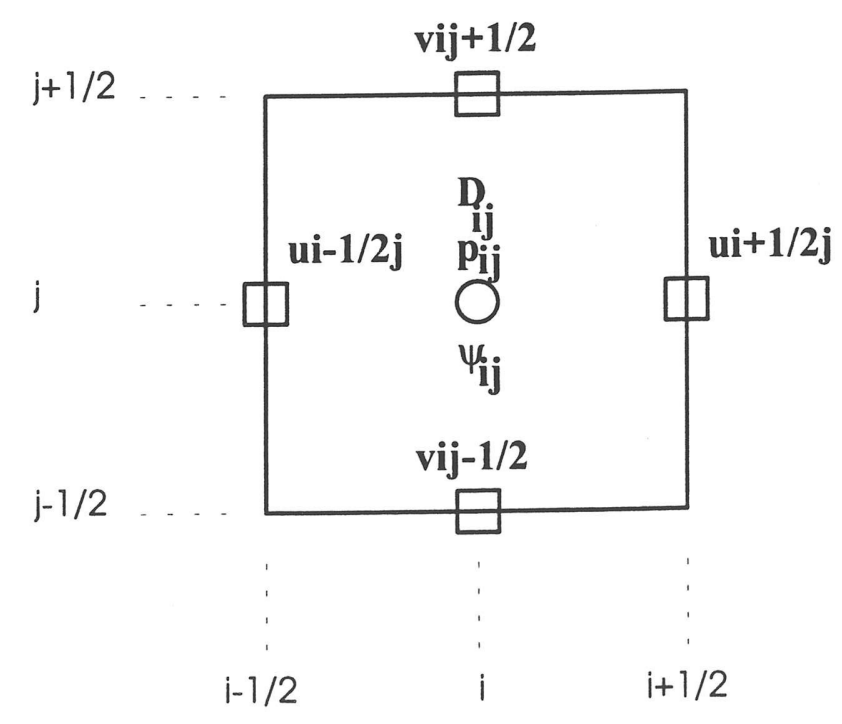

Fig. 3.2 : Configuração de uma célula. 


\section{Capítulo 4}

\section{Visualização}

\subsection{Considerações Iniciais}

Visualização, o processo de utilização de computação gráfica sofisticada para obtenção de idéias e compreensão de dados complexos, está emergindo como uma tecnologia estratégica numa vasta área do mercado técnico e científico. Softwares de visualização são usados em grande variedade de áreas de aplicação, incluindo imagens médicas, sensoreamento remoto, química, engenharia, dinâmica de fluido, entre outras.

A visualização auxilia a extração de informações úteis e proveitosas de dados complexos e freqüentemente volumosos através do fornecimento de representações visuais. A visualização engloba técnicas de computação gráfica, processamento de imagens, visão computacional, projeto auxiliado por computador (CAD), processamento de sinais, estudos na área de interfaceamento com o usuário, ciência cognitiva e geometria computacional.

A tecnologia da Visualização Científica tem mudado significativamente a forma como cientistas realizam pesquisas. $\mathrm{O}$ enorme benefício obtido com a interação direta com grandes conjuntos de dados ou execução de simulações, introduziu uma nova tendência: a visualização interativa. Resultados de modelos passaram a ser apreciados numa forma dinâmica visual com possibilidade do usuário interagir com a apresentação visual dos dados. 
A área de Dinâmica de Fluido Computacional (DFC) é um tópico de grande importância devido sua enorme gama de aplicações, que vai desde estudos oceânicos, atmosféricos e astronômicos, até propriedades de metais sob alterações de temperatura. DFC aparece como uma área chave nas pesquisas sobre visualização científica, pela possibilidade de execução de simulações no computador para modelagem de processos complexos, e conseqüente necessidade de visualização de seus resultados [Rose91]. Técnicas como o acompanhamento de células de interesse em uma simulação ilustra a fusão entre computação gráfica e processamento de imagem digital [Samt94]. Muitos resultados produzem dados em três dimensões, e a representação visual efetiva desses dados tem produzido novas descobertas e entendimentos. A área de Visualização Volumétrica e métodos de Modelagem de Sólidos são contribuições efetivas e importantes. Novas técnicas visuais estão emergindo com a finalidade de extrair a natureza de dados de quatro ou mais dimensões.

\subsection{Aspectos da Visualização Computacional}

Inúmeras estratégias podem ser utilizadas para converter dados numéricos em imagens no computador. Uma das formas baseia-se na realização de planos de corte numa região de dados que compõem um volume, e conseqüente visualização bidimensional. Dessa forma, por exemplo, a representação visual desses dados pode ser feita através de um mapa de linhas de contorno, para dados escalares, ou vetores e linhas de corrente para informações vetoriais. 
O método de visualização baseado em pixels consiste na apresentação de uma imagem constituída por uma matriz de valores, onde cada valor é uma coleção de números descrevendo atributos de um pixel da imagem. Este tipo de representação é normalmente utilizado por dispositivos como radares, tomógrafos, satélites, scanners, etc. A essência desta estratégia consiste na transformação dos valores de dados de forma que estes representem cores. Uma grande variedade de técnicas podem ser usadas na produção de imagens de alta qualidade: interpolações nos dados, antialiasing, filtragens [Fole90].

Outra forma de visualização refere-se à representação de objetos tridimensionais. As técnicas de visualização são distintas para objetos geométricos manufaturáveis e para objetos que representam formas orgânicas e outros fenômenos naturais. Estes últimos demandam o uso de técnicas da modelagem procedural, como fractais e sistemas de partículas [Fole90], e possuem características de visualização específicas.

A representação visual de objetos geométricos tridimensionais deve apresentar alto grau de realismo de forma a não gerar interpretações ambíguas. Uma das etapas do processo de visualização trata do mapeamento de pontos do espaço tridimensional, onde se encontra o objeto, para um ambiente de duas dimensões: os dispositivos gráficos de visualização. Esta operação denomina-se Projeção. Projeções classificam-se de acordo com a posição do centro de projeção em relação ao plano de projeção. Se a distância entre eles for finita, a projeção é perspectiva, caso contrário, a projeção é paralela. As várias subclasses das projeções citadas acima são discutidas e ilustradas em [Suth74] . Outro aspecto a ser considerado é a determinação, a partir de uma descrição da cena, das linhas ou superfícies visíveis de cada objeto [Suth74] [Fole90]. Dentre os vários algoritmos desenvolvidos para remoção de linhas/superfícies escondidas destacam-se: Scan-Line [Watk70], Z-Buffer [Carp84], método da subdivisão de Warnock [Warn69] e Ray-Tracing [Roth82]. A cor 
associada a cada pixel é determinada através do cálculo da função de iluminação. O modelo de iluminação deve levar em conta o conjunto de propriedades da superfície e o conjunto de propriedades da fonte de iluminação. A superfície tem características de absorção, reflectância e transparência. A fonte de iluminação, responsável por efeitos de brilho e sombra, pode ser ambiental (paralela) ou pontual e a luz refletida de uma superfície pode ser do tipo re-radiação difusa e/ou reflexão especular. Dentre os algoritmos de "shading" que utilizam modelos de iluminação, destacam-se o "Flat Shading", o "Gouraud Shading" e o "Phong Shading" [Roge85] [Fole90]. Alguns métodos levam em conta a troca de energia luminosa entre todas as superfícies de uma cena, como por exemplo, o Ray-tracing recursivo e a Radiosidade. A modelagem de refrações, reflexões e sombras estão normalmente integradas a métodos de eliminação de superfícies ocultas.

Outro aspecto da visualização é a possibilidade de descrição de processos dinâmicos, através da técnica de animação visual. A naturalidade de uma animação está relacionada com o mundo físico. Sendo assim, uma melhor animação baseia-se na simulação detalhada que considera as dinâmicas do movimento. Na maioria das aplicações não é necessário um modelo dinâmico preciso para a seqüência de animação, necessitando simplesmente que o movimento pareça real para a visão humana.

Uma técnica simples de animação de imagens é a apresentação de quadros seqüencialmente, com possibilidade de suavização do movimento através da interpolação de quadros-chaves. A interpolação de quadros chaves representa uma alternativa à técnica básica do processo de animação convencional. De uma forma simplificada, tal problema corresponde ao processo de geração de quadros intermediários para uma seqüência de imagens em movimento, sendo dado o primeiro e o último quadro. A essência deste processo está na determinação das correspondências entre os quadros, isto é, quais partes ou 
pontos do primeiro quadro devem ser mapeados ou transformados em quais partes ou pontos do último quadro. Este processo é conhecido como "inbetweening" ou interpolação de formas. Uma vez que essas correspondências estejam estabelecidas, suas trajetórias e suas transformações através do tempo devem ser determinadas [Reev81]. Uma abordagem simples usa interpolação linear entre os quadros, entretanto esta técnica não apresenta a naturalidade desejada, já que a movimentação de objetos e imagens são realizados bruscamente. Isto se deve ao fato da interpolação linear não gerar derivadas contínuas [Fole90]. As descontinuidades na direção e na velocidade do movimento produzidas pela interpolação linear podem ser evitadas com a interpolação por splines.

A técnica de Composição de imagens é utilizada na apresentação do movimento de um objeto frente a uma imagem de fundo que permanece inalterada. A técnica "Morphing" tem sido muito utilizada em produções cinematográficas e "clips" de música para animação de metamorfoses [Hall93]. A técnica de animação do tipo algorítmico parametrizado baseia-se na manipulação dos diversos parâmetros de um modelo para produzir uma animação ao longo do tempo.

Para o desenvolvimento deste trabalho serão abordados aspectos de visualização de contornos de funções de duas variáveis onde são apresentadas técnicas para sua realização. 


\subsection{Processamento de mapas de contornos}

Dados que podem ser visualizados na forma de um mapa de contornos são encontrados em diversos tipos de aplicações. Um exemplo bastante comum é o mapa de contornos representando a elevação de um terreno como uma função da posição em uma região geográfica bidimensional. Outras variáveis comumente representadas na forma de mapas de contornos são pressão e temperatura.

Qualquer função contínua por partes, de valor único e de duas variáveis contínuas independentes pode ser representada na forma de um mapa de contornos. O problema da construção de um mapa de contornos pode ser estabelecido da seguinte forma:

Seja $w=w(x, y)$ uma função de duas variáveis definida num domínio retangular $R$ $(a \leq x \leq b, c \leq y \leq d)$. Deseja-se desenhar $n$ curvas de níveis, tal que : $w(x, y)=c k, k=1, \ldots, n$.

Métodos para contorno de funções de duas variáveis podem ser de dois tipos genéricos: métodos baseados em grade e métodos de busca de contornos. Métodos baseados em grade são os mais utilizados devido à sua simplicidade, e consistem na definição de uma grade sobre a área de plotagem e desenho dos contornos em cada célula da grade. Torna-se necessário utilizar uma grade fina o bastante para permitir uma boa visualização através de aproximações lineares, embora alguns algoritmos usem aproximações quadráticas [Sibs81]. Métodos de busca de contornos usam um ou mais pontos sobre um contorno para predizer a posição do próximo ponto. Eles podem requerer a primeira e a segunda derivada da função a ser contornada em cada passo da execução [Suff84], e possuem codificação complicada se comparados com os métodos baseados em grades. Entretanto, possuem a vantagem de fornecer um tamanho de passo que varia de acordo com a curvatura dos contornos. 
Para este trabalho foram estudados alguns métodos de contorno de funções baseados em grade de dados. A próxima seção descreve as características dos métodos apresentados por Cottafava e Le Moli e de métodos que usam funções quádricas para interpolação dos pontos da grade. O método apresentado por Suffern usa quadtrees para realizar uma subdivisão adaptativa da área de plotagem, de forma a produzir uma grade fina somente na vizinhança de um contorno.

\subsubsection{Métodos para Contorno de Funções de Duas Variáveis}

O método apresentado por Cottafava e Le Moli [Cott69] segue o esquema de busca de um ponto da curva de nível e rastreamento do domínio até que a mesma termine. $\mathrm{O}$ método requer uma etapa preliminar em que é verificado se cada aresta da grade é ou não interceptada pela linha de contorno, sem cálculo ou armazenamento das coordenadas de intersecção. Os pontos de intersecção são encontrados numa etapa posterior, explorando-se as arestas ao longo do contorno de uma célula.

Após a busca e armazenagem das arestas interceptadas pela linha de contorno, segue a análise e solução dos seguintes problemas: o problema local, que está relacionado com o comportamento da linha no interior de uma célula e nas células adjacentes e o problema global, que inspeciona o comportamento da linha com relação ao domínio total.

Problema local: se uma aresta de célula $(\mathrm{i}, \mathrm{j})$ é interceptada por uma curva de nível, então alguma outra aresta desta célula também é interceptada pela mesma linha. Neste método é considerada uma ordem de inspeção das arestas da célula, no caso: LESTE, SUL, OESTE E NORTE. 
O processo de rastreamento de uma linha de contorno após a deteç̧ão da célula interceptada pela mesma, segue o esquema:

- buscar a outra aresta que armazena uma intersecção (seguindo a ordem descrita acima);

- marcar a intersecção para que não seja novamente encontrada;

- calcular as coordenadas do ponto de intersecção;

- prosseguir com a análise para a célula adjacente à aresta com a última intersecção encontrada, repetindo-se o processo.

Através deste método uma linha de contorno é constituída por uma seqüência ordenada de pontos, sendo possível usar um esquema de interpolação para ligar estes pontos.

Problema global: consiste na busca do ponto inicial e final da linha de contorno. A busca do ponto inicial é realizada varrendo-se as arestas em uma determinada ordem até encontrar uma intersecção. A linha é construída até o seu término. O processo de varredura prossegue a partir do ponto em que foi interrompido. A posição de término será sempre a fronteira da área de plotagem se a curva for aberta, ou o ponto final será o mesmo que o inicial para curvas fechadas.

Constituem degenerações tratadas neste método:

a) uma célula interceptada mais que duas vezes por uma curva de nível;

b) uma curva que passa exatamente sobre um ponto da grade.

Marlow e Powell [Mar176] sugeriram e implementaram uma técnica eficiente e robusta para contornar uma função quadrática dentro de um triângulo. Esta técnica tornouse atrativa para a busca de um método de contorno de uma função pela aproximação da 
mesma por uma função quadrática por partes com diferenciabilidade contínua através das fronteiras das arestas do triângulo, e união destes contornos parciais, formando contornos completos. Uma otimização deste método foi proposta por Sibson e Thomson [Sibs81], que usaram dados de valores e gradientes, e assim puderam acomodar quadráticas por partes juntamente com elementos finitos para a construção da função de aproximação. Neste trabalho introduziu-se elementos formados por dezesseis triângulos. Quando tais elementos são justapostos para formar uma grade, a função resultante é continuamente diferenciável através das linhas da grade.

A subdivisão empregada é mostrada na fig.4.1. Consiste de quatro sub-elementos retangulares organizados no padrão São Jorge (terminologia de Lancaster), cada qual sendo internamente subdividido no padrão Santo André. O trabalho baseia-se na propriedade da intersecção das tangentes de funções quadráticas.

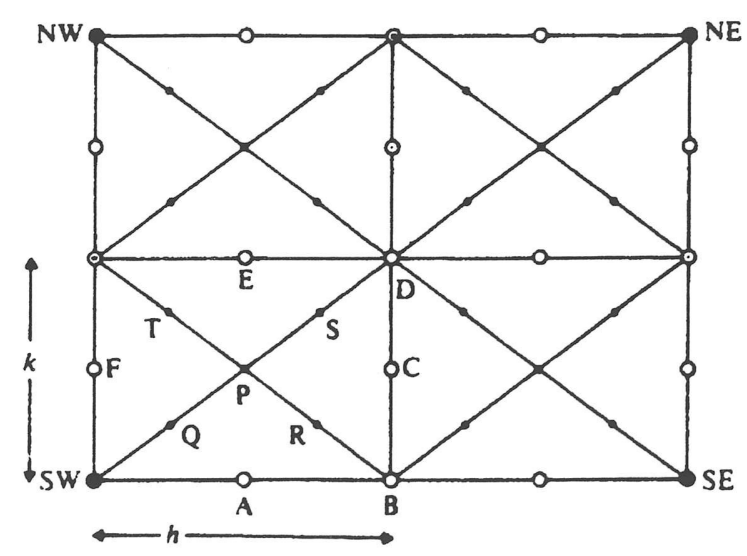

Fig. 4.1 : Subdivisão empregada no método de Sibson e Thomson.

Suffern [Suf90] apresentou dois algoritmos baseados em grades para contorno de funções de duas variáveis sobre áreas de plotagem quadradas. Estes algoritmos alcançaram uma eficiência considerável através do uso da técnica de quadtrees para produzir uma 
subdivisão adaptativa da área de plotagem. Dessa forma, foram produzidas grades que são finas somente na vizinhança de um contorno ou cujo tamanho varia de acordo com a curvatura do contorno.

Quadtrees sao vastamente utilizados em ciência da computação e podem ser encontrados em diversas aplicações em computação gráfica e processamento de imagens. Em Samet [Same84] encontra-se uma pesquisa detalhada sobre os tipos e usos de quadtrees. Quadtrees são freqüentemente usados como estrutura de dados, embora os algoritmos aqui apresentados os utilizem somente para realizar uma subdivisão adaptativa e recursiva da área de plotagem.

Antes da apresentação dos algoritmos serão abordados alguns inconvenientes das técnicas de grade tradicionais para contorno de funções. As fig. 4.2 e 4.3 exemplificam algumas desvantagens destes métodos, onde são desenhados contornos da função $x^{2}+y^{2}+c=0$, no intervalo $c=0.1(0.1) 7.6$, usando uma grade $16 x 16$ (fig. 4.2). Embora os contornos mais externos sejam razoavelmente bons, os contornos mais internos possuem péssima apresentação. O uso de uma grade mais fina (fig. 4.3) irá exigir muitos passos para desenhar os círculos mais externos. Uma característica bastante indesejável dos algoritmos tradicionais é que para cada contorno traçado, a mesma grade uniformemente espaçada é usada em toda a área de plotagem e, muitas vezes, cada contorno existe somente em uma pequena parcela das células da grade. 


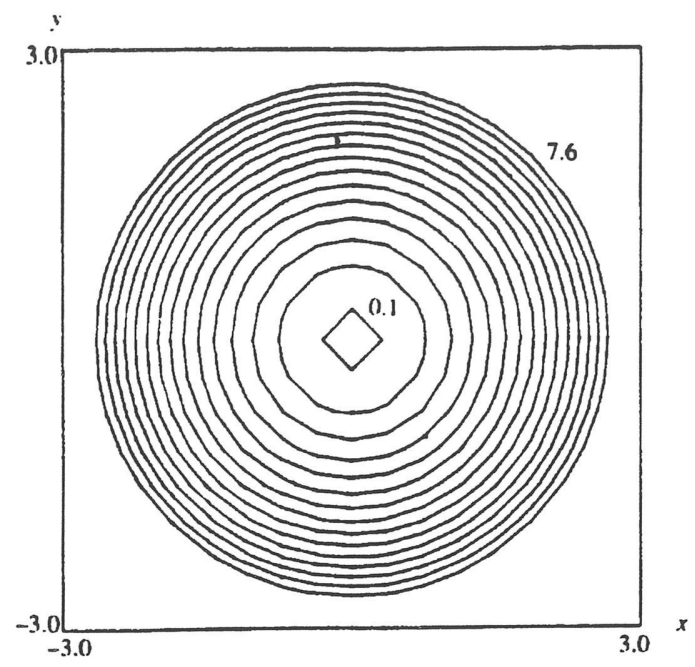

Fig. 4.2 Contorno da função $x^{2}+y^{2}-c=0$, para $c=0.1(0.1) 7.6$, usando o algoritmo tradicional com uma grade $16 \times 16$

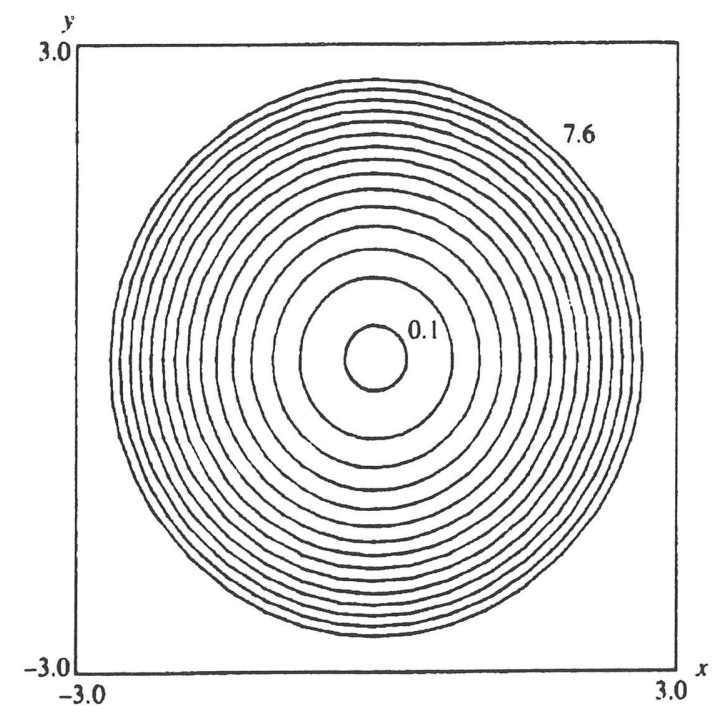

Fig. 4.3 Contorno da função $x^{2}+y^{2}-c=0$, para $c=0.1(0.1) 7.6$, usando o algoritmo tradicional com uma grade $64 \times 64$

O primeiro algoritmo proposto por Suffern restringe o número de células vazias que devem ser verificadas. Neste algoritmo, mostrado na fig. 4.4, o parâmetro depth corresponde à profundidade da árvore. Os outros parâmetros especificam as coordenadas $x$ e $y$ do canto inferior esquerdo da área de plotagem e sua dimensão $d$. Os valores das 
variáveis search_depth e plot_depth são fornecidos pelo usuário. A subdivisão da grade ocorre automaticamente até o nível search_depth, sem verificação da presença de contornos nos quadrantes. Ao alcançar serch_depth, a função contour_present checa a existência de contornos nos quadrantes. Qualquer quadrante contendo um segmento de contorno é novamente subdividido até o valor de plot_depth. A figura 4.5 mostra as grades usadas para contornar as curvas c=0.1 e c=7.6 da mesma função descrita acima, usando o algoritmo proposto, com search_depth=2 e plot_depth=6.

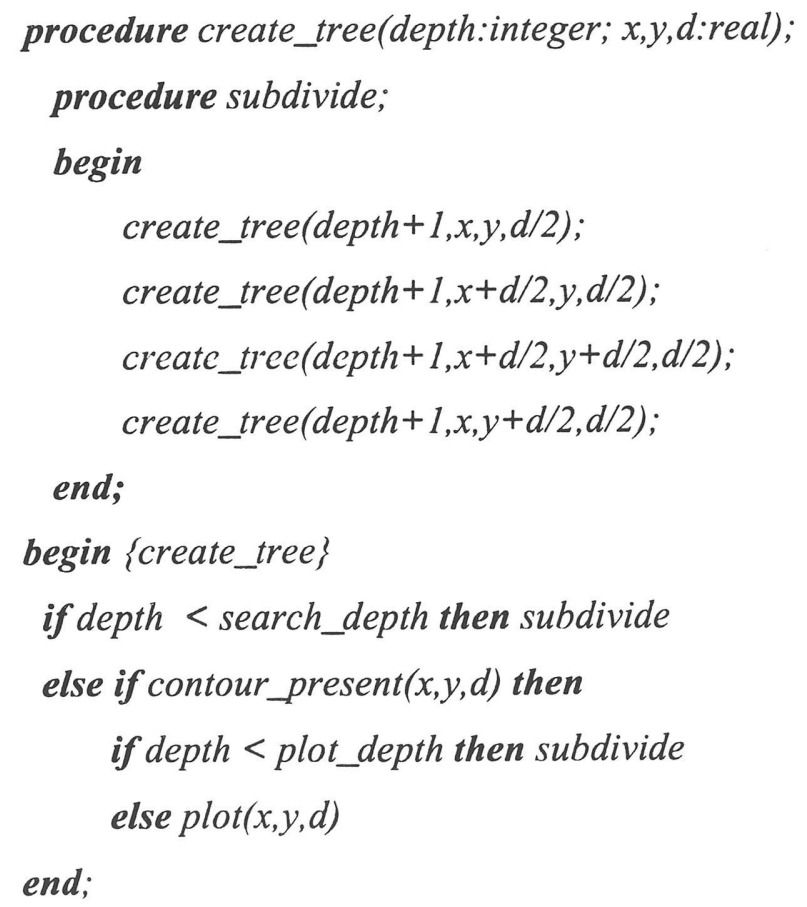

Fig. 4.4 Algoritmo 1 proposto por Suffern 


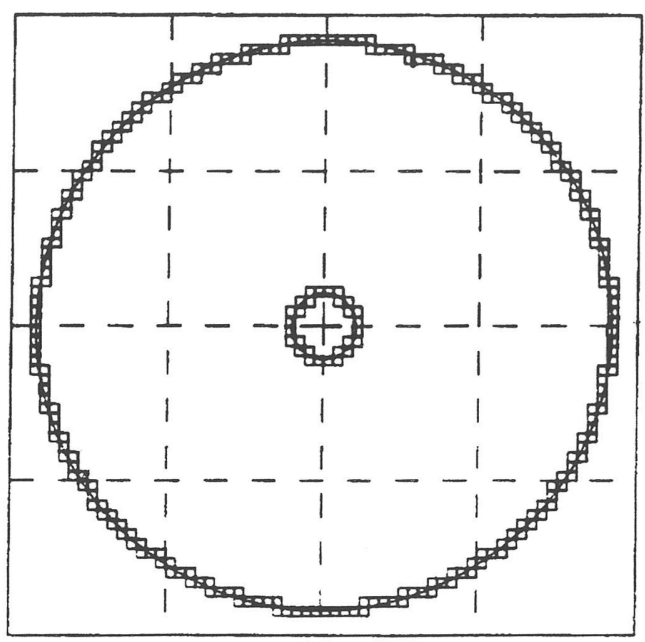

Fig. 4.5 Contorno da função $x^{2}+y^{2}-c=0$, para $c=0.1$ e 7.6, usando quadtrees com search_depth $=2$ e plot_depth $=6$.

Um segundo algoritmo substitue a constante plot_depth por uma função que calcula o raio de curvatura de $f(x, y)$ no plano $(x, y)$ em cada quadrante que contém um segmento de contorno. O nível de subdivisão depende da curvatura local da função, dessa forma, o tamanho do passo para plotagem passa a ser inversamente proporcional ao raio de curvatura dos contornos. A fig 4.6 exemplifica esta melhoria.

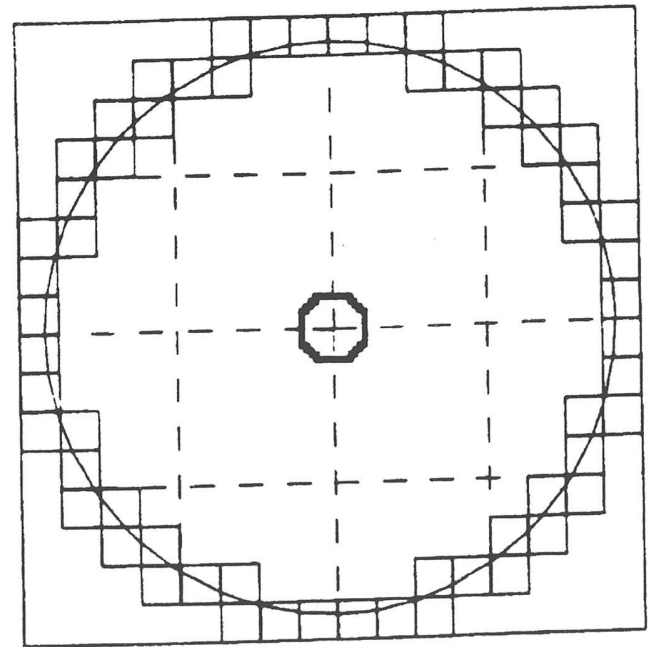

Fig. 4.6 Contorno da função $x^{2}+y^{2}-c=0$, para $c=0.1$ e 7.6, usando o algoritmo 2 com search_depth=2 


\section{Capítulo 5}

\section{O Modelador de Moldes e o Visualizador de}

\section{Escoamento de Fluidos}

\subsection{Considerações Iniciais}

A área de Dinâmica de Fluido Computacional caracteriza-se pelo amplo uso dos recursos da computação gráfica com o objetivo de analisar e validar os resultados de suas simulações. Em conexão com o Simulador de Escoamento de Fluidos FREEFLOW, foi desenvolvido um pacote gráfico que oferece facilidades para introdução de parâmetros do escoamento e dados do domínio, bem como possibilita a visualização gráfica dos resultados das simulações realizadas.

Este capítulo descreve a interface gráfica desenvolvida como apoio à utilização e validação dos resultados do Simulador FREEFLOW. Esta interface é composta pela integração dos módulos: Modelador de Moldes, Interface para Entrada de Dados e Monitoramento da Simulação e Visualizador de Escoamento de Fluidos. Embora estes três módulos sejam funcionalmente relacionados, cada um pode ser independentemente executado.

O Modelador de Moldes 2D é uma ferramenta de desenho interativa que permite a definição de forma rápida e fácil, do molde usado na simulação de escoamento de fluidos, ou seja, do domínio do escoamento. O programa conta com a possibilidade de construção 
de moldes através do instanciamento das primitivas segmento de reta, poli-linha, arco de circunferência, cubic-splines e B-splines e possue recursos para modificação de objetos modelados, como a movimentação, adição e remoção de pontos de controle, e realização de transformações geométricas.

Os diversos parâmetros necessários para configurar o escoamento a ser simulado são introduzidos e consistidos no módulo de entrada de dados, que é responsável pelo acionamento e monitoramento do programa FREEFLOW. Este módulo também possibilita a execução do Modelador de Moldes e do Visualizador de Escoamento de Fluidos.

Os resultados da simulação de escoamento de fluidos podem ser visualizados graficamente através do módulo de visualização. Os possíveis tipos de visualização incluem a apresentação num certo instante de tempo da região com fluido, da pressão, temperatura e velocidade, e da malha de células. O fluido pode ser visualizado na forma de partículas ou pela apresentação de sua fronteira. Mapas de contornos promovem uma visualização eficiente das variáveis do escoamento: pressão, temperatura e velocidade. A velocidade também pode ser analisada pela apresentação de vetores representando direção e magnitude. Os parâmetros que configuram os tipos de visualização disponíveis podem ser interativamente modificados de modo a aperfeiçoar a visualização. É possível sobrepor campos bem como verificar o comportamento do escoamento no decorrer do tempo, através do recurso de animação.

A seguir serão apresentadas as características da implementação do Modelador de Moldes, da Interface de Entrada de Dados para o Simulador de Escoamento de Fluidos e do Visualizador de Escoamento de Fluidos. A primeira seção contém uma descrição do sistema de janelas sobre o qual o trabalho foi desenvolvido. Uma seção é dedicada exclusivamente para descrição de aspectos gerais da implementação do pacote gráfico para 
o Simulador de Escoamento de Fluidos. As seções seguintes descrevem as características de cada módulo separadamente: o Modelador de Moldes, a Interface para Execução do Simulador e o Visualizador de Escoamento de Fluidos. A seção 5.7 apresenta alguns exemplos da geração de moldes por instanciamento de primitivas, e da visualização de algumas simulações realizadas pelo programa FREEFLOW. Esta seção também mostra as características de algumas janelas de interfaceamento com o usuário.

\subsection{Window, X Toolkit Intrinsics e Motif}

Um sistema de janelas manipula recursos do espaço da tela e dos dispositivos de interação, de maneira que muitas aplicações ou múltiplas visões de uma mesma aplicação possam compartilhar o "display". Um display é definido como uma workstation consistindo de um teclado, um mouse, e uma ou mais telas de vídeo. “Toolkits" são construídos sobre o sistema de janelas e fornecem ao projetista de aplicações um conjunto comum de técnicas de interação, impondo uma política de interfaceamento com o usuário. Sistemas Gerenciadores de Interface com o Usuário (SGIUs) fornecem um suporte genérico adicional, facilitando e reduzindo o tempo de desenvolvimento de interfaces gráficas [Fole90].

O presente trabalho está implementado sobre o ambiente de janelas X Window. Os módulos de Modelagem do Molde, Interface para Entrada de Dados para o Simulador de Escoamento de Fluidos e o Visualizador de Escoamento de Fluidos utilizam componentes de interface com o usuário definidos pelas bibliotecas X Toolkit Intrinsics (Xt) e Motif. 
Esta seção descreve alguns conceitos referentes ao sistema de janelas X, ao toolkit Intrinsics e à biblioteca Motif.

\subsubsection{Window}

O advento de computadores do tipo Estações de Trabalho (Workstations), caracterizados por integrarem num único pacote as tecnologias da computação gráfica, displays "bitmapped", entradas por teclado e mouse, e tornarem os computadores máquinas mais poderosas e fáceis de usar, acarretou na necessidade de desenvolvimento de softwares interativos que explorassem ao máximo as potencialidades gráficas dessas máquinas. $\mathrm{O}$ desenvolvimento do sistema de janelas X, conduzido pelo Projeto Athena do Massachusetts Institute of Technology (MIT), e pela Digital Equipment Corporation (DEC) correspondeu a estes anseios e possibilitou a construção de aplicações para estações de trabalho usando uma interface comum e portável. Atualmente o sistema de janelas X vem sendo adotado como padrão pela maioria dos fabricantes de workstations, já existindo também versões para computadores pessoais e supercomputadores .

O objetivo do sistema de janelas $\mathrm{X}$ é prover transparência de rede e um ambiente de operação independente de hardware. Estas características foram viabilizadas pelo fato do sistema X estar fundamentado sobre um "sistema de janelas base" que interage com o mundo externo através do protocolo de rede $\mathrm{X}$. O protocolo de rede $\mathrm{X}$ consiste de um conjunto pré-definido de pedidos e respostas entre dois processos. Um deles é o programa da aplicação (cliente) e o outro o programa que controla o display (programa servidor).

O programa servidor contém o código específico dos dispositivos da máquina e isola as aplicações das diferenças do hardware. Este programa permite o acesso do display por 
múltiplos clientes, interpreta as mensagens dos clientes (pedidos) executando as ações apropriadas, envia mensagens de eventos (pressionamento de teclado ou mouse, entre outros) ao programa da aplicação e manipula estruturas de dados como janelas, fontes, cursores, contextos gráficos, entre outras.

Os programas de aplicação não acessam o protocolo de rede diretamente, mas sim um pacote de subrotinas em linguagem $\mathrm{C}$, denominado Xlib [Nye92]. O Xlib fornece funções para conexão com o servidor, criação de janelas, desenhos de gráficos, respostas a eventos. As chamadas de rotinas do Xlib são traduzidas para comandos do protocolo X e enviadas para o servidor através da rede.

Uma aplicação X mínima deve conter as seguintes etapas:

- Configurar uma conexão com a máquina;

- Criar uma janela;

- Informar o gerenciador de janelas das propriedades da janela;

- Criar recursos X, tais como contextos gráficos;

- Mapear a janela para a tela (torná-la visível);

- Solicitar os eventos de entradas de interesse;

- Ler e interpretar os eventos solicitados;

- Gerar saídas gráficas;

- Terminar o programa quando a aplicação for completada.

Uma aplicação $\mathrm{X}$ bem estruturada deve estar preparada para responder a todos os tipos de eventos que ocorrerem em qualquer ordem. Muitos eventos ocorrem numa workstation sem o controle direto do programa de aplicação. Uma Mensagem de Evento 
informa a aplicação que algo que afeta a aplicação ocorreu. As mensagens de eventos permitem que a aplicação saiba o que o usuário ou outras aplicações fizeram.

Existem uma grande variedade de tipos de eventos. Cada aplicação solicita os tipos de eventos que deseja interceptar, ou seja, ela informa o servidor que deseja receber mensagens de eventos notificando-a de cada ocorrência de cada tipo de evento solicitado.

\subsubsection{Toolkit Intrinsics}

Um toolkit é uma biblioteca de subrotinas de interface com o usuário. Do ponto de vista de um usuário, um toolkit possui o objetivo de padronizar e modularizar as ações, como por exemplo ativar menus e botões . Do ponto de vista do programador, o objetivo do toolkit é simplificar o projeto e o desenvolvimento de interfaces com usuários.

Os toolkits são construídos sobre o sistema de janelas base $\mathrm{X}$ através da interface Xlib. Três toolkits são fornecidos pelo sistema de janelas X padrão: o X Toolkit Intrinsics ou Xt, desenvolvido inicialmente pela DEC e Projeto Athena do MIT; o Xrlib, desenvolvido pela HP; e o ATK, Toolkit de Andrew, desenvolvido pela Carnegie-Mellon University e pela IBM.

O objetivo do Xt é fornecer uma camada orientada a objetos que suporta abstrações de interfaces com o usuário, denominados "widgets" [Nye93]. Um "widget" é um componente de interface reutilizável e configurável que opera independentemente da aplicação. O Xt fornece um mecanismo geral para produção de "widgets", de modo que estes possam ser construídos pelo programador de aplicação ou possam estar disponíveis em bibliotecas de componentes de interface pré-estabelecidas. Tais bibliotecas são 
denominadas "widgets sets". Um "widget set" fornece componentes de interface comumente utilizados, tais como botões, barras de rolagem, menus "pulldown", etc. Logo, o "widget set" é que define uma política para a interface com o usúario, estabelecendo um estilo para esta interface. Dois "widgets sets" comercialmente disponíveis são o Motif da Open Software Foundation (OSF) e o OPEN LOOK da AT\&T e Sun Microsystems.

Um "widget set" define classes de widgets. Uma área de desenho, assim como uma barra de rolagem constituem classes de widgets. Cada vez que se cria um "widget", realizase o instanciamento de uma das classes pré-definidas. Uma classe de "widgets" possui certas características fixas que são comuns a todos os instanciamentos daquela classe e certas características que podem ser modificadas. Cada característica configurável é denominada "resource". Através do mecanismo de "resource" as classes de widgets declaram variáveis que representam atributos do widget. Os "resources" podem ser configurados dentro do programa de aplicação, ou em arquivos de padrões específicos da aplicação (app-defaults). As características de um widget podem ser herdadas de outras classes mais básicas. A fig.5.1 mostra a hierarquia de herança de classes para o conjunto de widgets Motif.

O X Toolkit é projetado de forma que o código que implementa a interface com o usuário e o código da aplicação sejam mantidos separados. Dessa forma, alterações em uma dessas duas partes não afeta a outra, possibilitando o fácil transporte da aplicação para outros sistemas com estilo de interfaceamento com o usuário distinto. Os seguintes mecanismos são utilizados para ligar widgets com funções da aplicação: "callbacks", “actions" e "event handlers". Listas callbacks são recursos do widget. A aplicação adiciona funções a estas listas que serão executadas sempre que uma condição pré-definida for satisfeita, não sendo necessariamente um evento. Rotinas actions são invocadas diretamente 
pelo Xt em resposta a eventos especificados na "translation table". Uma translation table é um recurso do widget que contém um mapeamento entre eventos ou seqüências de eventos e nome de rotinas actions. Os event handlers usam um mecanismo de seleção de eventos similar ao usado pelo Xlib.

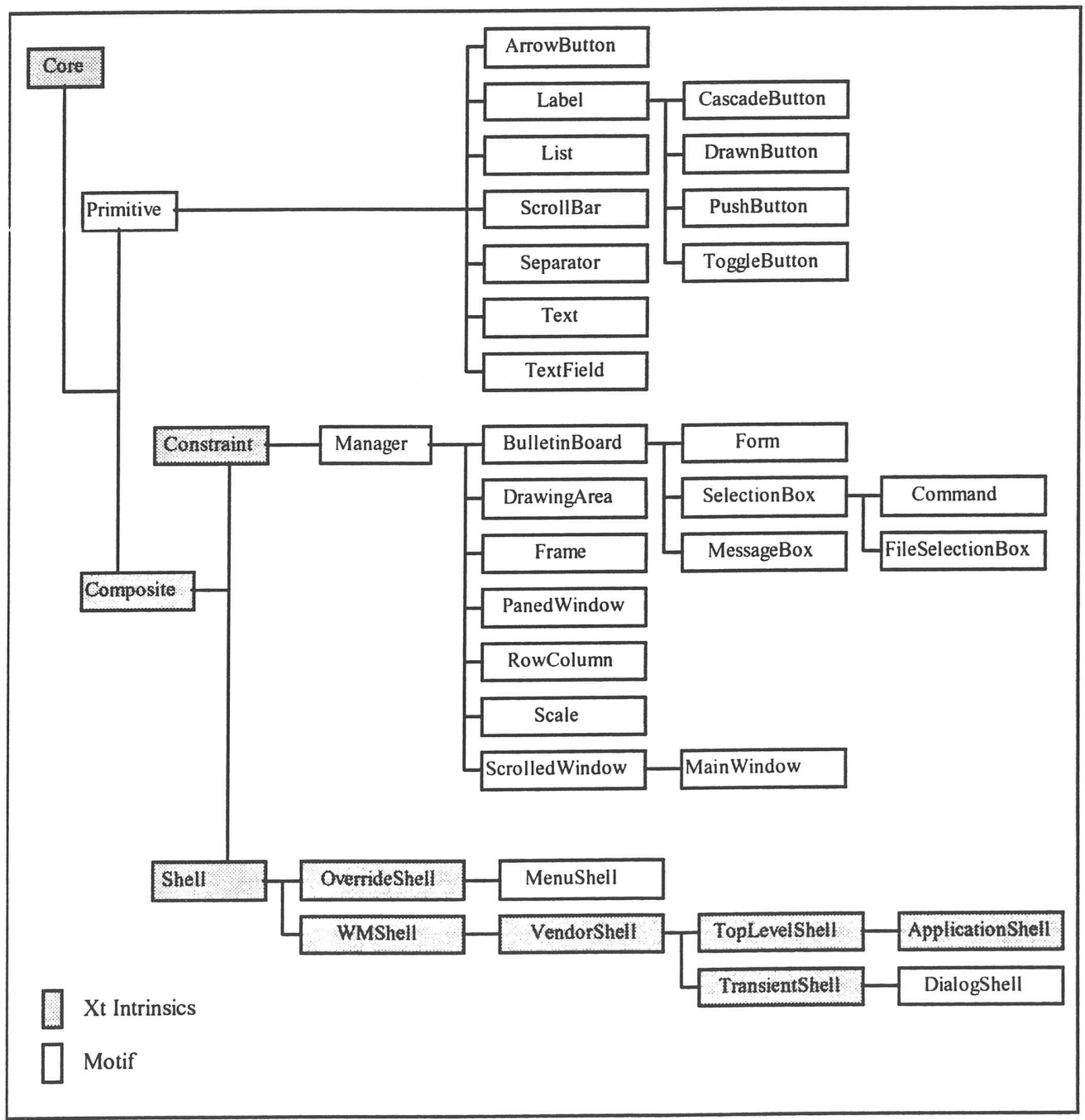

Fig. 5.1 : Hierarquia de classes para o conjunto de widgets Motif e Xt 


\subsubsection{Motif}

A biblioteca Motif $(\mathrm{Xm})$ define um conjunto completo de classes de widgets suficiente para implementar a maioria das necessidades de uma interface com o usuário [Hell94][Ferg94]. O Motif é completamente independente do sistema de janelas, entretanto, para aprimorar a portabilidade e a robustez, a Open Software Foundation (OSF) decidiu implementar a Interface de Usuário Gráfica (GUI) Motif usando o sistema de janelas X Window e o X Toolkit Intrinsics como plataforma para a Interface do Programador de Aplicações (API).

A fig 5.2 representa um modelo de interfaceamento entre as diversas camadas usadas na construção de uma aplicação.

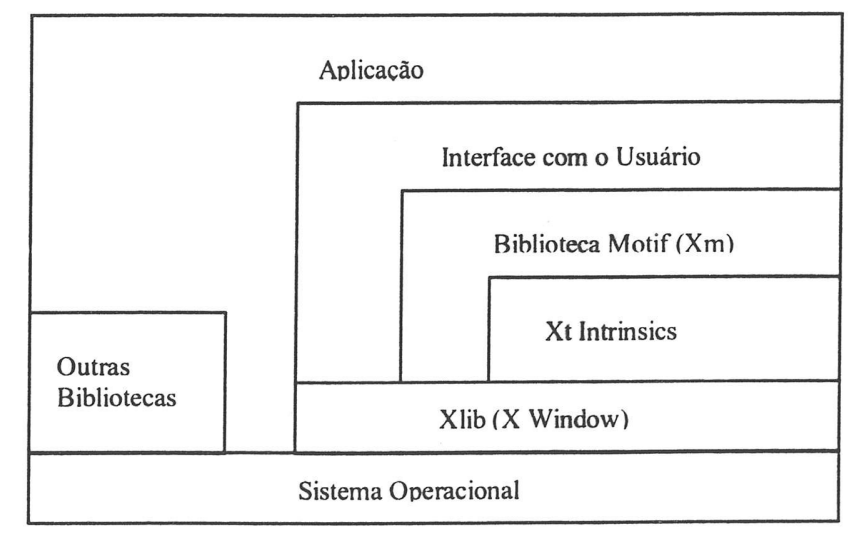

Fig. 5.2 Modelo de interfaceamento entre camadas na construção de uma aplicação

Como mostrado na fig. 5.2, uma aplicação pode interagir como todas as camadas do sistema de janelas, com o sistema operacional e com outras bibliotecas, tais como a biblioteca matemática, bancos de dados, etc. Entretanto a porção de interface com o usuário deve se restringir ao uso do Motif, $\mathrm{Xt} \iota \mathrm{X}$ Window para manter a portabilidade entre diferentes computadores e sistemas operacionais. 
Uma interface Motif é criada usando tanto a biblioteca Motif $(\mathrm{Xm})$ como também a biblioteca Intrinsics $(\mathrm{Xt})$. O Xt fornece meios para criar e configurar recursos dos widgets, enquanto que o $\mathrm{Xm}$ fornece os widgets propriamente ditos, além de rotinas e funções de conveniência para construir grupos de widgets que poderão ser usados como um único componente de interface com o usuário.

Todas as aplicações em Motif possuem a seguinte estrutura básica:

1. Inclusão do arquivo de cabeçalho para o Motif (Xm/Xm.h);

2. Inclusão dos arquivos de cabeçalho públicos de cada classe de widget usada pela aplicação;

3. Registro da função callback de suporte à internacionalização (XtSetLanguageProc);

4. Ativamento do Toolkit ( funções XtAppInitialize ou XtVaAppInitialize);

5 Criação de widgets, o que requer uma chamada à função XtVaCreateManagedWidget para cada widget criado. No Motif existem funções individuais para criação de widgets.

6. Registro de funções "callbacks", ações ("actions") e/ou manipuladores de eventos (“event handlers") para os widgets criados;

7. Ativamento dos widgets criados através da função XtRealizeWidget(). Esta função é chamada apenas uma vez na aplicação, e tem por objetivo criar e mapear as janelas na tela;

8. Execução do laço de processamento de eventos chamando a função XtAppMainLoop(). Neste ponto, o Xt toma o controle da aplicação e opera os widgets criados. 


\subsection{Aspectos Gerais da Implementação}

Os programas que compõem este pacote gráfico foram desenvolvidos sobre o sistema de janelas X Window e seguem o estilo Motif de projeto e construção de interfaces com o usuário. Os módulos foram implementados de forma que o código da aplicação fosse independente do código da interface. Esta independência é possível pelo uso de chamadas à rotinas "callbacks" e "actions" associadas com os elementos de interface criados.

Os programas foram desenvolvidos em workstations Alpha Digital 3800, com versões executando em ambientes linux-PC, IBM Risc 6000, e Sun Solaris. Para facilitar a compilação e instalação dos programas em diferentes plataformas UNIX, foi usado o utilitário imake. O imake usa arquivos Imakefiles para gerar makefiles específicos para cada plataforma, e requer a especificação de regras, definições e opções de compilação[Husa94].

Para organizar e facilitar a busca de arquivos e programas do pacote construído foi estabelecida uma hierarquia de diretórios fixa a partir de um diretório topo. Uma variável do sistema (FreeTOPDIR) deve conter a informação do diretório topo a partir do qual inicia a seguinte estrutura de diretórios: 


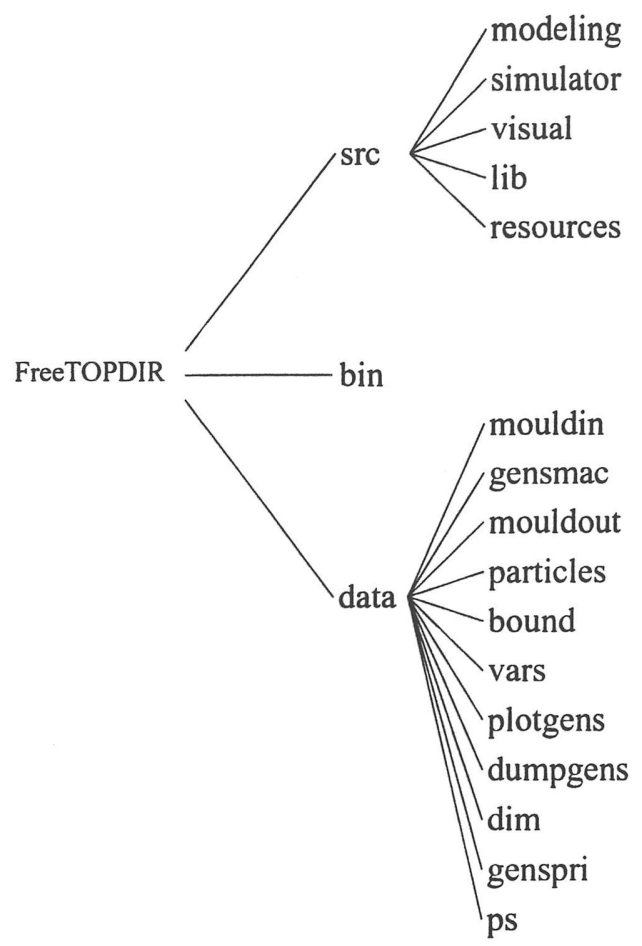

Fig.5.3 Estrutura de diretórios do sistema Simulador de Escoamento de Fluidos

O diretório src contém os códigos fontes de todos os programas desenvolvidos neste trabalho. Os subdiretórios modeling, simulator e visual contém os programas dos módulos de modelagem de moldes, simulação do escoamento e visualização dos resultados do simulador, respectivamente. $\mathrm{O}$ subdiretório lib possui os programs fontes de rotinas e funções de interface comuns a todos os módulos desenvolvidos e que compõem a biblioteca libXs. Alguns exemplos dessas rotinas são: procedimento para construção e formatação da barra de menus, rotinas para apresentação de caixas de diálogo informativas e de alerta, funções para apresentação lado a lado dos widgets rótulo e texto, escrita em um widget rótulo usando o formato do printf. O subdiretório resources possui os recursos dos widgets de cada módulo de interface implementado.

O diretório bin armazena os programas executáveis do trabalho desenvolvido. 
O diretório data está subdividido em outros que guardam dados manipulados pelo pacote gráfico do Simulador de Escoamento de Fluidos. O Simulador de Escoamento de Fluidos utiliza informações de configuração contidas nos arquivos do diretório FreeTOPDIR/data/gensmac. Cada um desses arquivos possue um campo que aponta para o arquivo de molde associado. Os moldes à disposição do simulador, construídos pelo Modelador de Moldes são armazenados no diretório FreeTOPDIR/data/mouldin.

Os resultados da simulação ficam distribuídos nos subdiretórios da seguinte forma:

FreeTOPDIR/data/moldeout - contém a plotagem do molde em cada passo da simulação;

FreeTOPDIR/data/particles - é utilizado para armazenar informações das partículas do fluido;

FreeTOPDIR/data/bound - contém informações sobre a fronteira do fluido;

FreeTOPDIR/data/vars - armazena dados de pressão, temperatura, velocidade e configuração da malha de células;

FreeTOPDIR/data/plotgens - armazena arquivos com informações de dados gerados pelo simulador. Trata-se de variáveis com significado físico mostradas na forma não dimensional;

FreeTOPDIR/data/dumpgens - contém arquivos com informações necessárias para uma nova execução a partir do ponto em que a simulação foi interrompida; FreeTOPDIR/data/dim - possui informações das dimensões da grade usada na simulação;

O diretório FreeTOPDIR/data/genspri armazena arquivos de impressão com informações dos parâmetros de configuração de escoamentos. Estes arquivos somente 
são criados se o usuário optar pela impressão do mesmo na interface do simulador de escoamento.

O diretório FreeTOPDIR/data/ps é utilizado pelo programa de visualização do escoamento, para armazenar arquivos postscripts com imagens visualizadas.

\subsection{O Modelador de Moldes}

O módulo de modelagem possibilita a definição do domínio do escoamento do fluido. Trata-se de um editor gráfico interativo que permite a descrição de objetos bidimensionais através do instanciamento de primitivas gráficas e manipulação desses objetos utilizando recursos da computação interativa. Algumas tarefas interativas implementadas foram o "rubberband", o "dragging" e o uso de manipuladores de controle.

Uma técnica construtiva bastante útil em janelas de desenho é o esticamento ("rubberbanding"), que pode ser exemplificado na construção de uma linha. O usuário inicialmente aperta um botão para definir a posição inicial da linha. O movimento do cursor na janela de desenho mostrará a linha em diferentes posições até que um novo botão seja pressionado fixando o final da linha. A fig. 5.4 exemplifica as operações descritas acima.
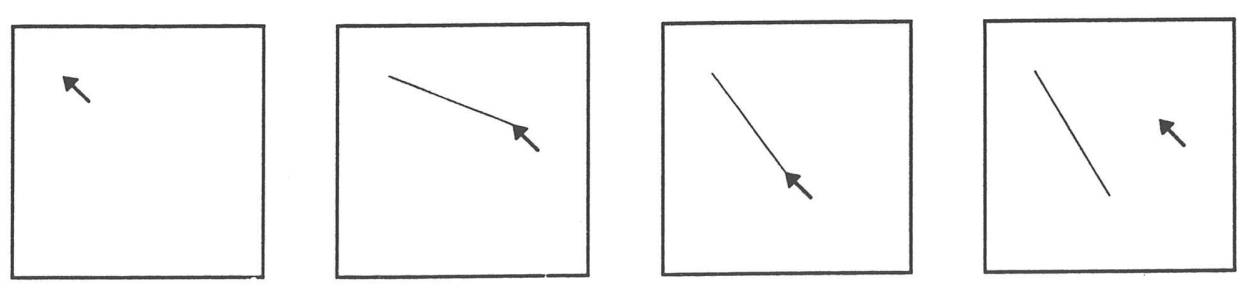

Fig. 5.4: Exemplo da técnica "Rubberbanding" 
A manipulação dinâmica conta com recursos de arrastamento ("dragging") e uso de manipuladores de controle ("handles") para modificar entidades geométricas previamente criadas.

A técnica de arrastamento permite a movimentação de um objeto (translação), alterando-o de uma posição para outra sob o controle do mouse, como mostrado na fig.5.5 . A rotação dinâmica de um objeto pode ser realizada de forma similar, com inclusão da identificação do ponto ou eixo sobre o qual a rotação irá ocorrer.
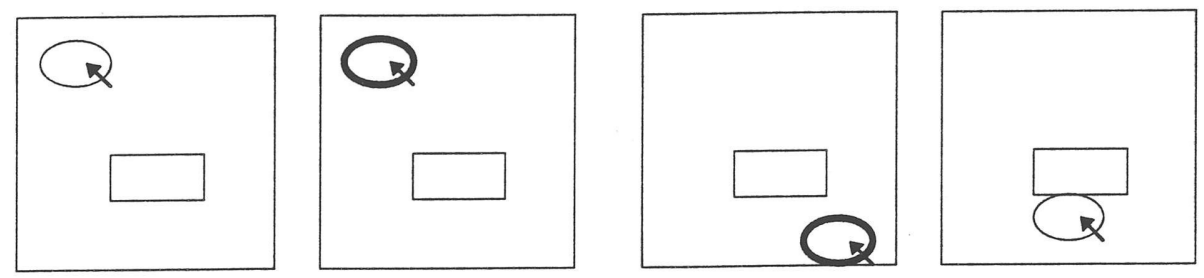

Fig. 5.5: Exemplo de "Dragging” na movimentação de um objeto

O conceitos de manipuladores é prático em operações de escalamento e deformação. A fig. 5.6 mostra um objeto com cinco manipuladores que são apresentados na forma de pequenos quadrados. No caso da modificação de pontos individuais, por exemplo, num dos vértices de um polígono, o usuário aponta um vértice, seleciona e arrasta o mesmo até sua nova posição e este é novamente desenhado. Para curvas B-splines, manipuladores permitem a modificação dos pontos de controle que definem a curva, e conseqüente alteração na forma da curva. Manipuladores fornecem um código visual prático para indicar a seleção de um objeto. 

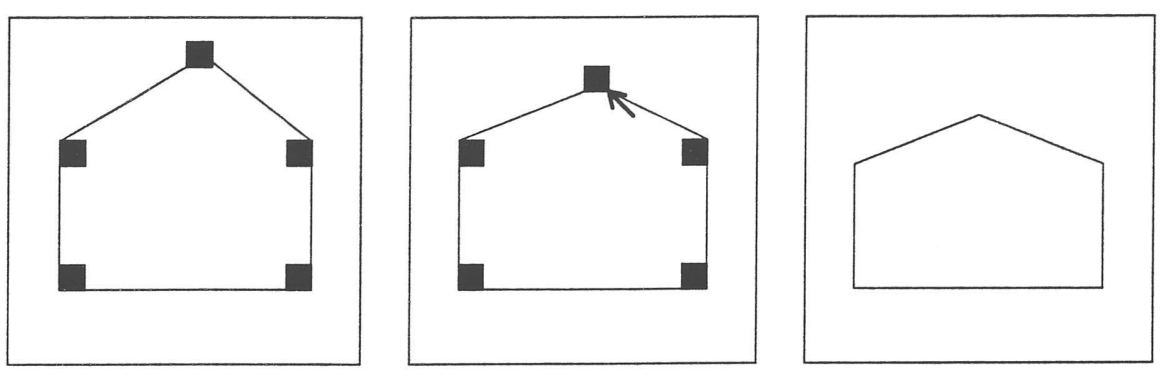

Fig. 5.6: Exemplo do uso de "handles" para alteração da forma de um objeto.

As sub-janelas componentes do módulo de modelagem do molde serão descritas a seguir:

- barra de menus: proporciona acesso às opções de gerenciamento de arquivos, edição de primitivas, configuração e ajuda. As operações de manipulação de arquivos disponíveis incluem a carga de um arquivo já construído, a gravação, a gravação com novo nome, e a remoção de arquivos. A opção de edição permite a introdução textual de primitivas para a construção do molde. Os pontos que definem uma primitiva são introduzidos de forma textual, no formato esperado pelo programa FREEFLOW. Assim que uma primitiva é descrita e consistida, sua representação gráfica é apresentada na área de desenho. O usuário pode combinar as duas formas de construção do molde, a interativa usando mouse sobre a área de desenho e através do fornecimento de identificadores. A opção de configuração habilita o usuário a definir os valores mínimos e máximos para dimensionar a área de desenho de acordo os valores desejados e permite configurar a régua de auxílio à descrição de moldes. A opção "Ajuda" da barra de menus possui uma facilidade que permite uma forma simples e prática de esclarecimento sobre um determinado botão ou alguma opção. Trata-se da op̧ão “on context”, onde o usuário ao selecioná-la, terá o cưsor modificado e poderá clicar sobre o widget que deseja obter informações. 
- painel de comandos e controle: é constituído por menus de ícones que listam as primitivas gráficas disponíveis: as poli-linhas, os segmentos de reta representando inflows e outflows, o arco de circunferência, as splines cúbicas e as B-splines. Também apresentam botões com funções de modificação de primitivas desenhadas através de operações com o cursor do mouse nos manipuladores de controle da primitiva (mover, adicionar, remover) ou nas primitivas diretamente (mover, remover, rotacionar). As primitivas podem ser unidas entre si pelos pontos extremos e constituem um objeto único. Um botão tipo menu de opção define se o estado corrente é o de conexão ou não das primitivas selecionadas. Este painel também apresenta o nome do arquivo de molde correntemente em uso. Existe uma janela que mostra o tamanho da reta que está sendo desenhada durante uma operação de construção da primitiva gráfica de acordo com os valores definidos pelo usuário para dimensionar a área de desenho.

- área de desenho: é a região onde os moldes são construídos e visualizados. Os efeitos da manipulação do mouse variam de acordo com o modo de desenho ativo no momento. Se a escolha for de seleção de uma primitiva gráfica, é esperado que seja definido o primeiro ponto da primitiva pelo pressionamento e liberação do botão esquerdo do mouse. As posições que o cursor do mouse assumir irão mostrar um segmento de reta conectado (rubberband). A janela do painel de controle irá mostrar o tamanho deste segmento de reta durante o movimento e até a sua fixação. A escolha da primitiva arco de circunferência irá esperar a introdução de três pontos pertencentes ao arco e os inflows e outflows esperam a especificação de dois pontos. Cada ponto deve ser marcado com o pressionamento e liberação do botão esquerdo do mouse. As primitivas poli-linhas, splines e B-splines necessitam de um evento que avise o fim da introdução dos pontos de controle. Este ponto é marcado pelo pressionamento do botão direito do mouse. Os pontos internos 
são marcados pelo pressionamento e liberação do botão esquerdo do mouse. Se o modo ativo for o de conexão de primitivas, o ponto inicial da primitiva passa a ser o último da última primitiva desenhada. As opções de manipulação de pontos de controle das primitivas esperam a seleção de um manipulador de controle. Os pontos que pertencem a duas primitivas (ponto de conexão), quando são movimentados, possibilitam a modificação das duas primitivas conectadas. A remoção e adição de pontos só é permitida para poli-linhas, cubic splines e B-splines, não podendo ser realizadas em pontos de conexão entre primitivas. As operações sobre a primitiva identificam o pressionamento do botão esquerdo do mouse sobre algum ponto da primitiva;

- régua: uma facilidade adicional incluída no modelador é a apresentação de duas réguas: uma horizontal, acima da área de desenho, e outra vertical, do lado direito da mesma. As diferentes posições do cursor sobre a área de desenho fazem movimentar o ícone "seta" sobre as réguas, informando a posição em que se encontra o cursor no momento, dessa forma o usuário poderá definir com mais exatidão os pontos que deseja marcar;

O simulador de escoamento de fluidos impõe restrições às primitivas de desenho que descrevem o domínio do fluido (molde), como por exemplo, o ângulo do arco não pode ser maior que noventa graus, inflows e outflows devem ser retas perpendiculares ao eixo xy. Estas restrições são observadas a cada acionamento da rotina de desenho da primitiva, sendo realizados procedimentos específicos para cada situação de não obediência a alguma regra. No caso da especificação do arco, por exemplo, é apresentada uma caixa de diálogo avisando a ocorrência do problema e os pontos usados na construção do arco são apagados. No caso da especificação de inflows e outflows é verificada se a reta desenhada assemelhase mais a uma reta horizontal ou a uma vertical. O desenho é fixado naquele eixo em que 
ela mais se aproximar. Outra consistência executada é a verificação da não intersecção entre as retas formadas pela união, na seqüência em que foram construídos, dos pontos de controle das primitivas gráficas.

Além da facilidade gráfica proporcionada pelo modelador, outra característica interessante é a independência do molde com os demais parâmetros necessários para a execução do simulador. Um mesmo molde pode ser usado em diferentes configurações de escoamento de fluidos. Esta independência tornou-se possível com o arquivamento dos moldes criados, o que possibilita, também, a recuperação e modificação dos moldes já construídos.

Como visto na descrição geral do sistema, o modelador gera e recupera arquivos de moldes do diretório "FreeTOPDIR/data/mouldin".

Os programas fontes, arquivos de cabeçalho, arquivos de pixmaps, que compõem o módulo de modelagem encontram-se no diretório "FreeTOPDIR/src/modeling".

\subsection{A Interface de Entrada de Dados para o Simulador}

Este módulo é responsável pela introdução de dados que caracterizam o escoamento a ser simulado. O simulador requer a introdução de informações do domínio e da configuração do escoamento para a sua execução. O domínio do escoamento descreve o molde dentro do qual a simulação do escoamento de fluidos é realizada, com informações de aberturas para entrada e saída de fluido. Entre os dados que configuram o escoamento podemos citar: número de passos no tempo, escalas de comprimento e velocidade, 
indicador de molde em movimento, espaçamento inicial da malha de células, tipo do modelo, viscosidade, etc.

A definição dessas informações antes da construção deste módulo era realizada colocando-se cada valor de variável em posições específicas dentro de um arquivo ASCII. Esta forma de entrada de dados dá margem a diversos tipos de erros, tais como, digitação de valores inconsistentes, erro no posicionamento da variável, além de tornar bastante trabalhosa a descoberta dos possíveis enganos. Muitas vezes um erro na especificação dos dados de entrada só era percebido após uma longa execução do simulador de escoamento de fluidos. O processo original de execução de simulador não possuía um mecanismo que distinguisse tipos diferentes de configurações de escoamentos e seus respectivos resultados, pois estes eram mantidos em arquivos com nomes fixos que eram substituídos a cada nova execução.

A implementação do módulo de entrada de dados e gerenciador da execução do simulador de escoamentos de fluidos facilitou a introdução de dados e implementou a manutenção e a manipulação de diversos arquivos de configuração do escoamento e dos resultados da simulação.

Este módulo foi construído utilizando-se diversos elementos de interface da biblioteca MOTIF, X Intrinsics e Xlib, como por exemplo, barra de menus, menus "pulldown", rótulos (labels), texto, lista de rolagem, área de desenho, caixas de diálogo. A barra de menus proporciona acesso às opções de manipulação de arquivos de configuração de escoamentos, execução e monitoramento da simulação, execução dos módulos de modelagem de moldes e de visualização do escoamento de fluidos, além da opção de ajuda.

Valores padrões são usados para definir a situação inicial dos dados de entrada assim que a aplicação é iniciada. O usuário poderá modificar os campos desejados e salvar a 
configuração num arquivo ou abrir um arquivo já existente. Está disponível também, a opção de impressão do arquivo de configuração corrente. Neste módulo o usuário poderá remover arquivos de configuração indesejados (arquivos do diretório data/gensmac).

O domínio do escoamento pode ser escolhido através de um menu que lista os nomes dos arquivos construídos pelo Modelador de Moldes. Uma janela apresenta o conteúdo textual do arquivo selecionado no formato esperado pelo programa FREEFLOW e outra apresenta o conteúdo na forma gráfica. Cada nova seleção atualiza ambas as janelas. $\mathrm{O}$ usuário pode executar o Modelador de Moldes para desenhar um novo molde ou modificar algum já existente.

Todos os campos que representam dados de entrada possuem um rótulo associado descrevendo o tipo do dado a ser introduzido. Este rótulo é construído usando o widget "label" do Xt Intrinsics. Este widget possui o recurso conjunto de caracteres do rótulo ("label string") que pode ser configurado num arquivo de padrões da aplicação (appdefaults). Este recurso foi utilizado permitindo o uso de rótulos em diferentes línguas sem necessidade de compilação do código.

O acionamento da execução do simulador considera os dados de entrada do arquivo de configuração do escoamento correntemente em uso. Antes do acionamento da execução é realizada uma verificação da consistência dos valores em cada campo. A rotina de consistência irá analisar todos os dados de entrada e apresentará uma caixa de diálogo informando a ocorrência do erro caso este exista. Nesta janela são apresentados o campo inconsistente e os valores válidos para aquele campo. É possível, durante a execução, visualizar os comandos do simulador que descrevem a etapa atual da simulação e apresentam algumas variáveis para checagem. A execução do simulador é facilmente interrompida caso necessário ou desejado. 
O visualizador também pode ser acionado, durante ou após a simulação, permitindo a verificação dos resultados através de gráficos.

A opção ajuda possui a mesma característica daquela descrita na seção Modelador de Moldes (opção “on context”). Neste módulo, a escolha desta opção fará aparecer uma janela contendo uma descrição do dado de entrada e mostrando os valores válidos para o dado em questão.

\subsection{O Visualizador de Escoamento de Fluidos}

O módulo de visualização (Visfreeflow) dos resultados do simulador de escoamento de fluidos permite a visualização gráfica do fluido, do domínio do escoamento e das propriedades do escoamento de fluidos.

O visualizador possui uma barra de menus disposta horizontalmente no topo da janela da aplicação com opções de manipulação de arquivos, escolha de tipos de variáveis para visualização, modificação de configurações, animação e ajuda. Um widget área de desenho proporciona a apresentação gráfica dos resultados da simulação.

O simulador de escoamento de fluidos sofreu algumas alterações de modo a possibilitar distinção entre diferentes configurações de simulações e facilitar o acesso pelo módulo de visualização. Cada configuração de dados de entrada para o simulador passou a ter um nome associado, e este nome é também utilizado para distinguir os arquivos de saída do simulador. Dados de um determinado passo no tempo ficam armazenados em um arquivo distinto, dessa forma tornando o tempo de acesso a um dado do início da simulação 
igual ao acesso a outro no final da simulação, e permitindo a visualização de campos mesmo antes do témino da simulação.

Ao selecionar uma configuração de escoamento para visualização, o usuário tem acesso aos dados gerados para esta configuração no tempo inicial. Uma janela para escolha de outros instantes no tempo pode ficar permanentemente aberta, e a seleção de um novo tempo (índice para plotagem ou iplot) provocará a atualização dos campos visualizados para o novo instante no tempo.

Os seguintes campos estão disponíveis para visualização: partículas de fluidos, bordo do fluido, pressão, velocidade, temperatura, domínio do escoamento e malha de células. É possível sobrepor campos, como por exemplo, visualizar o molde, o bordo do fluido e a pressão simultaneamente.

Os dados de saída do simulador possuem formatos distintos, e conseqüentemente, resultam em diferentes formas de visualização. $\mathrm{O}$ molde e ejetores são constituídos por segmentos de retas e arcos. As partículas e o bordo do fluido são representados por suas coordenadas no eixo xy. As variáveis pressão, temperatura e velocidade e as células de estado são representadas por matrizes de dados.

A visualização do domínio do escoamento é realizada pelo desenho de primitivas gráficas retas e arcos. As partículas de fluidos são mostradas como uma nuvem de pontos, enquanto que o bordo do fluido é desenhado unindo-se pontos por segmentos de reta e possui uma op̧̧ão de preenchimento ou não da região com presença de fluido. Possui facilidades para preenchimento de fluidos com cores distintas.

A velocidade é apresentada na forma de segmentos de reta direcionados, onde os diferentes tamanhos dos segmentos representam a intensidade, e setas indicam a direção do movimento das partículas de fluido. Para este tipo de visualização pode-se modificar o 
tamanho do segmento de reta que representa a maior intensidade da velocidade. Para que seja obtida uma noção mais precisa da intensidade de velocidade é possível fazer sua visualização através de mapas de contornos.

Uma forma bastante apropriada de visualização de dados escalares disponíveis na forma de grade consiste na construção de um mapa de contornos. O programa Visfreeflow possibilita a apresentação gráfica das variáveis pressão, temperatura e magnitude da velocidade através de mapas de contorno. Dois métodos de construção de contornos estão disponíveis: o primeiro, denominado "tradicional", segue o esquema proposto por Cottafava [Cott 69], com algumas modificações e o segundo utiliza quadtrees [Suff90] para realizar subdivisões adaptativas na grade de dados.

O método tradicional sofreu alterações com relação a etapa inicial de verificação e armazenamento das posições das arestas com presença de contornos. Esta etapa foi suprimida, sendo criada uma variável que armazena as arestas já pesquisadas a medida que a busca é realizada. As arestas pertencentes a fronteira do domínio de plotagem são analisadas primeiramente para a busca de contornos abertos. As arestas interiores são varridas desconsiderando-se aquelas marcadas como já pesquisadas. Para melhorar o aspecto visual de mapas de contorno baseados em grades não muito finas, foi introduzida a opção de suavização de linhas através de interpolações splines cúbicas.

O método que utiliza quadtrees constitue uma opção adicional para o traçado de contornos. Esta técnica apresenta vantagens na eficiência do algoritmo para casos em que os contornos existem somente em uma pequena região da área de plotagem, como é o caso das variáveis do programa FREEFLOW. Entretanto, alguns inconvenientes deste método é a possibilidade de não encontrar contornos muito pequenos que se localizam em quadrantes menores que o determinado pelo valor da profundidade da busca (serch_depth). O 
algoritmo implementado não realiza o cálculo do raio da curva para criar mais subdivisões na área de plotagem pelo fato deste processo exigir muito processamento para o cálculo de derivadas. Os parâmetros profundidade de busca e profundidade de plotagem podem ser modificados pelo usuário. Um tratamento especial foi realizado para traçar curvas em grades retangulares e cujo tamanho do quadrante resultava em valor ímpar. Como este algoritmo não persegue uma linha de contorno até o seu final, torna-se trabalhosa a tarefa de rotular e suavizar as linhas de contornos.

As rotinas de visualização gráfica das saídas do simulador foram implementadas de modo a serem independentes dos elementos de interface com o usuário e altamente configuráveis. No caso de curvas de nível geradas pelo método tradicional estão disponíveis as seguintes opções de configuração: o espaçamento entre as curvas de nível pode ser determinado das seguintes formas, automaticamente, onde fica fixado o número de curvas, faz-se uma busca pelo menor e maior valor e calcula-se o espaçamento; especificando-se o valor médio e o espaçamento desejado; ou definindo-se a quantidade de curvas de nível para plotagem especificando-se cada valor que se deseja contornar. O intervalo de valores que se deseja observar também pode ser determinado pela escolha dos valores mínimos e máximos para as linhas de contorno. As linhas de contorno podem ser monocoloridas ou podem usar cores distintas para cada valor da curva. Foi implementada uma opção de rotulação das linhas no gráfico ou apresentação de uma legenda com informações sobre os valores em cada nível (linhas representadas com cores distintas). O usuário tem opção de visualizar linhas ou contornos preenchidos.

Para informar sobre a resolução da malha de células usada na simulação existe a opção "grid" que apresenta a grade de células utilizada na simulação, superposta aos gráficos apresentados. 
Todos os campos visualizados podem ser animados. A janela de controle da animação permite a escolha do quadro inicial e final, animação passo a passo controlada pelo mouse ou animação automática, onde o usuário poderá alterar a velocidade da animação mesmo durante a sua execução usando o widget barra de rolagem.

Para permitir uma melhor apresentação gráfica foi implementada a opção de criação do arquivo para impressão no formato postscript.

\subsection{Exemplos}

Alguns exemplos da geração de moldes usando o Modelador 2D e de tipos de visualizações proporcionados pelo Visfreeflow são mostrados a seguir. Esta seção também contém gráficos que apresentam algumas janelas de interface com o usuário.

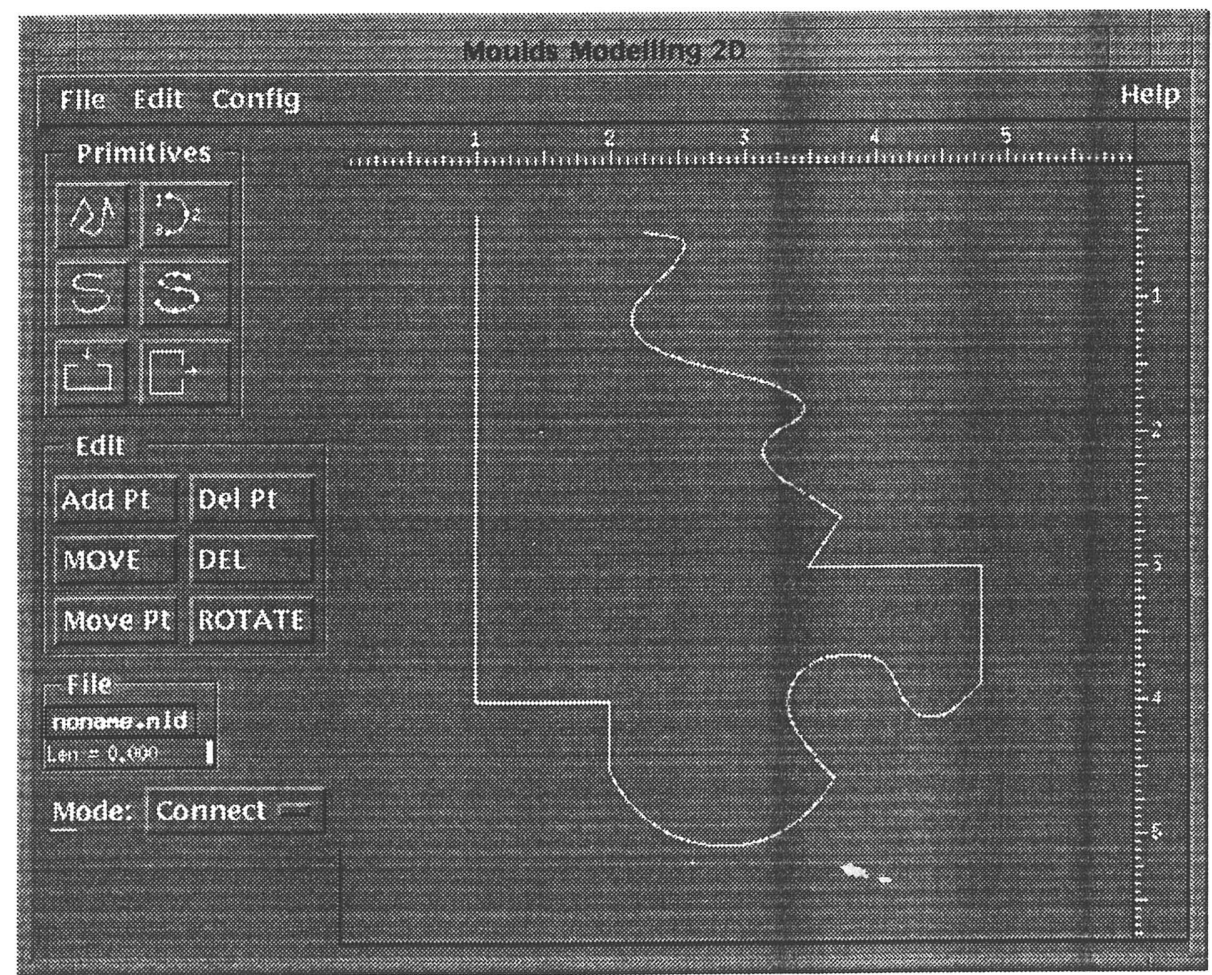

Fig. 5.7: Exemplo de molde construído com poli-linhas, arcos de cincunferência, splines e Bsplines. 


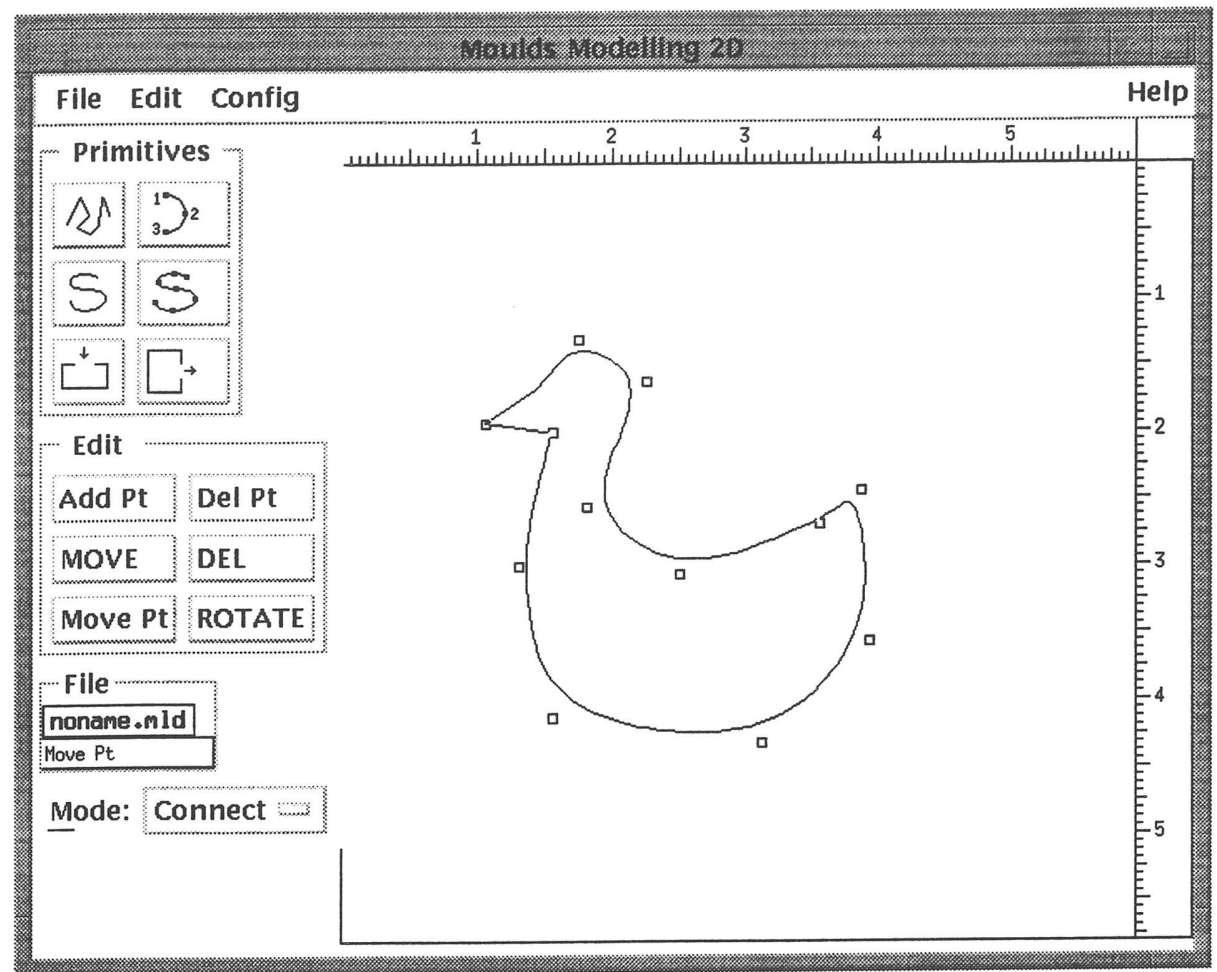

Fig. 5.8: Exemplo de um molde construído com B-splines e poli-linhas e com a operação "Move $\mathrm{Pt}$ " acionada.

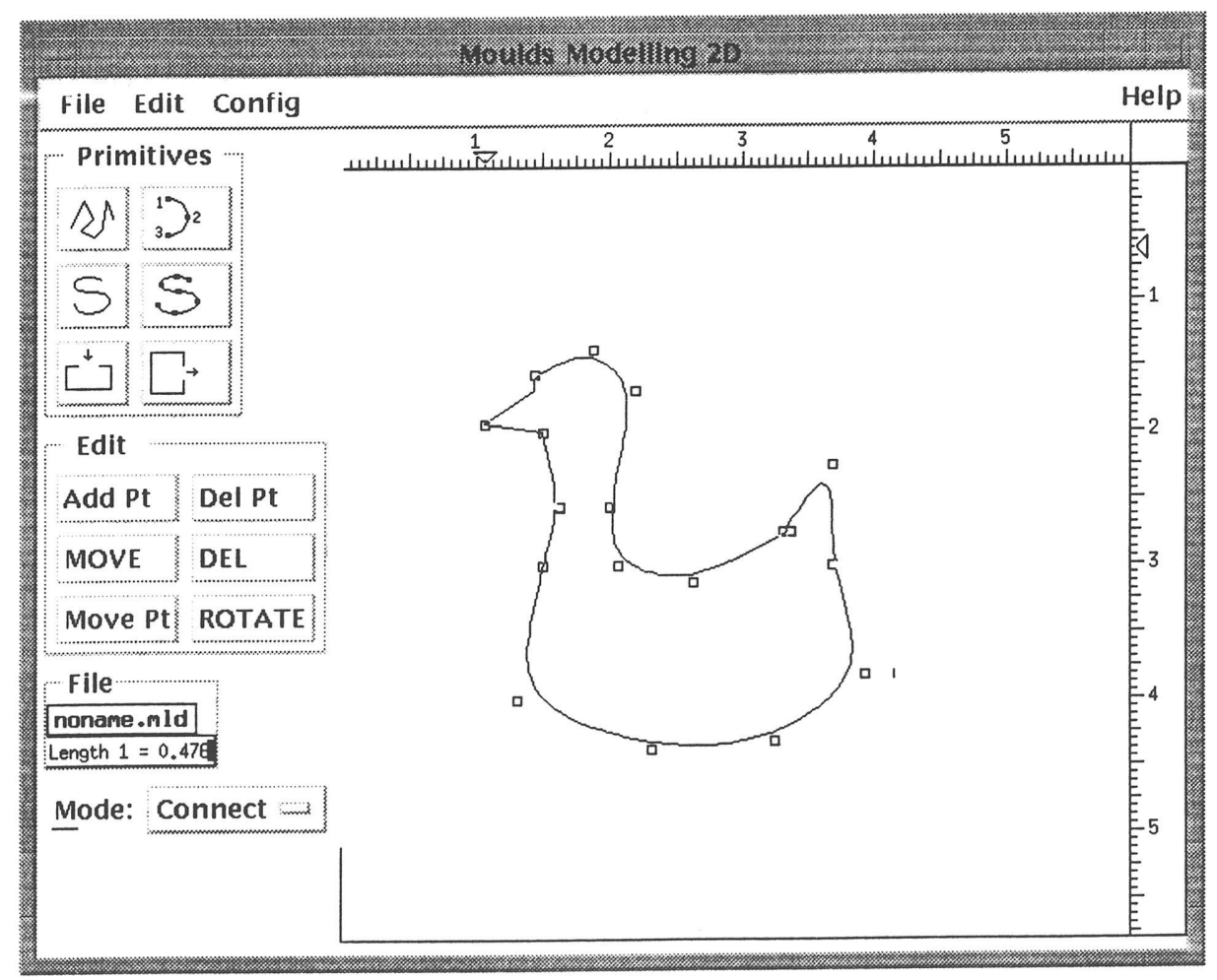

Fig. 5.9: Exemplo de um molde construído com B-splines e poli-linhas após operações de movimentação e adição de pontos. 


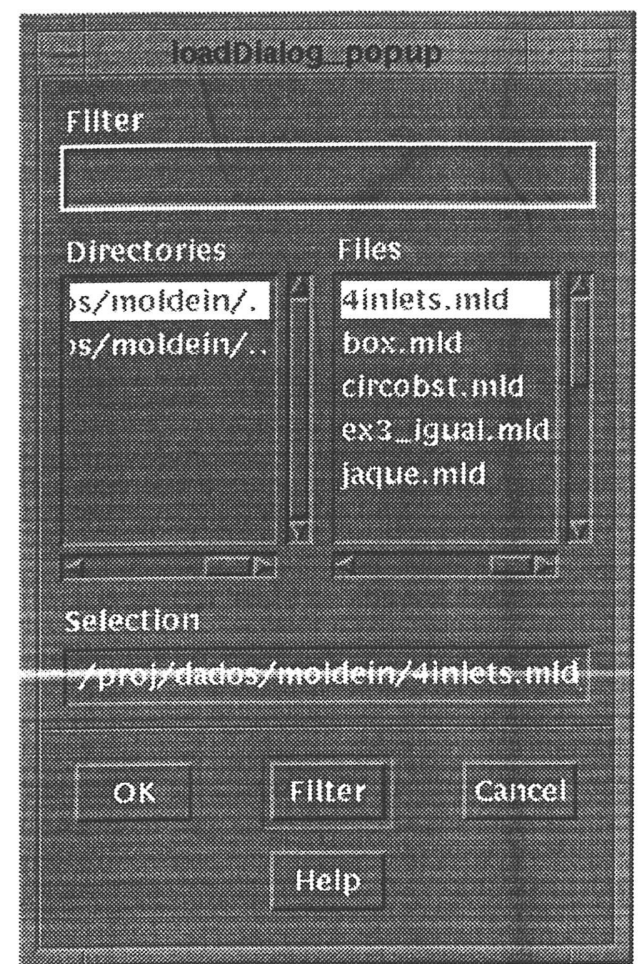

Fig. 5.10: Janela para carga de um arquivo de molde

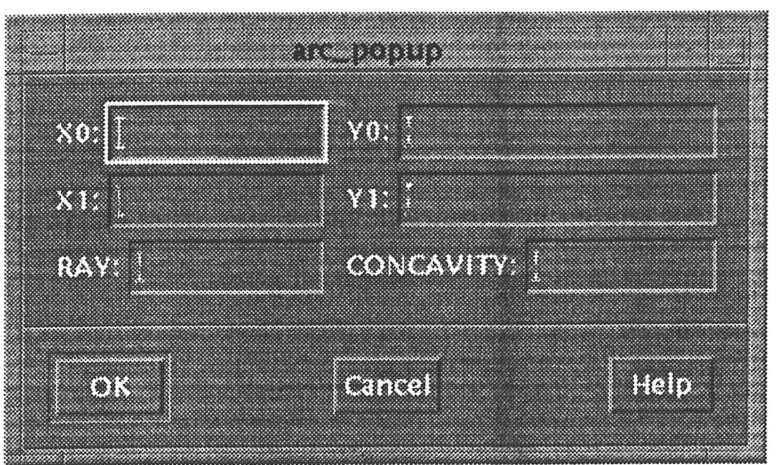

Fig. 5.11: Janela para introdução de dados no Modelador no formato do programa FREEFLOW

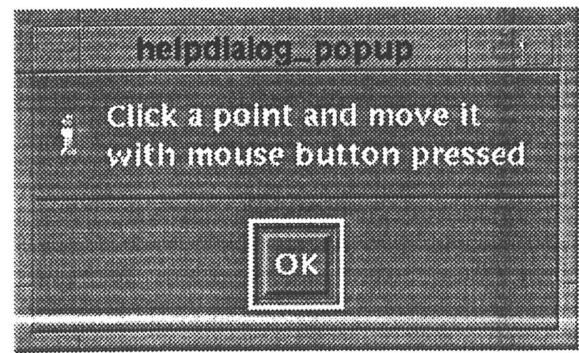

Fig. 5.12: Exemplo de uma caixa de diálogo de ajuda após a escolha da opção "on context" e clicagem sobre o botão "Move Pt" para movimentação de um ponto de controle 


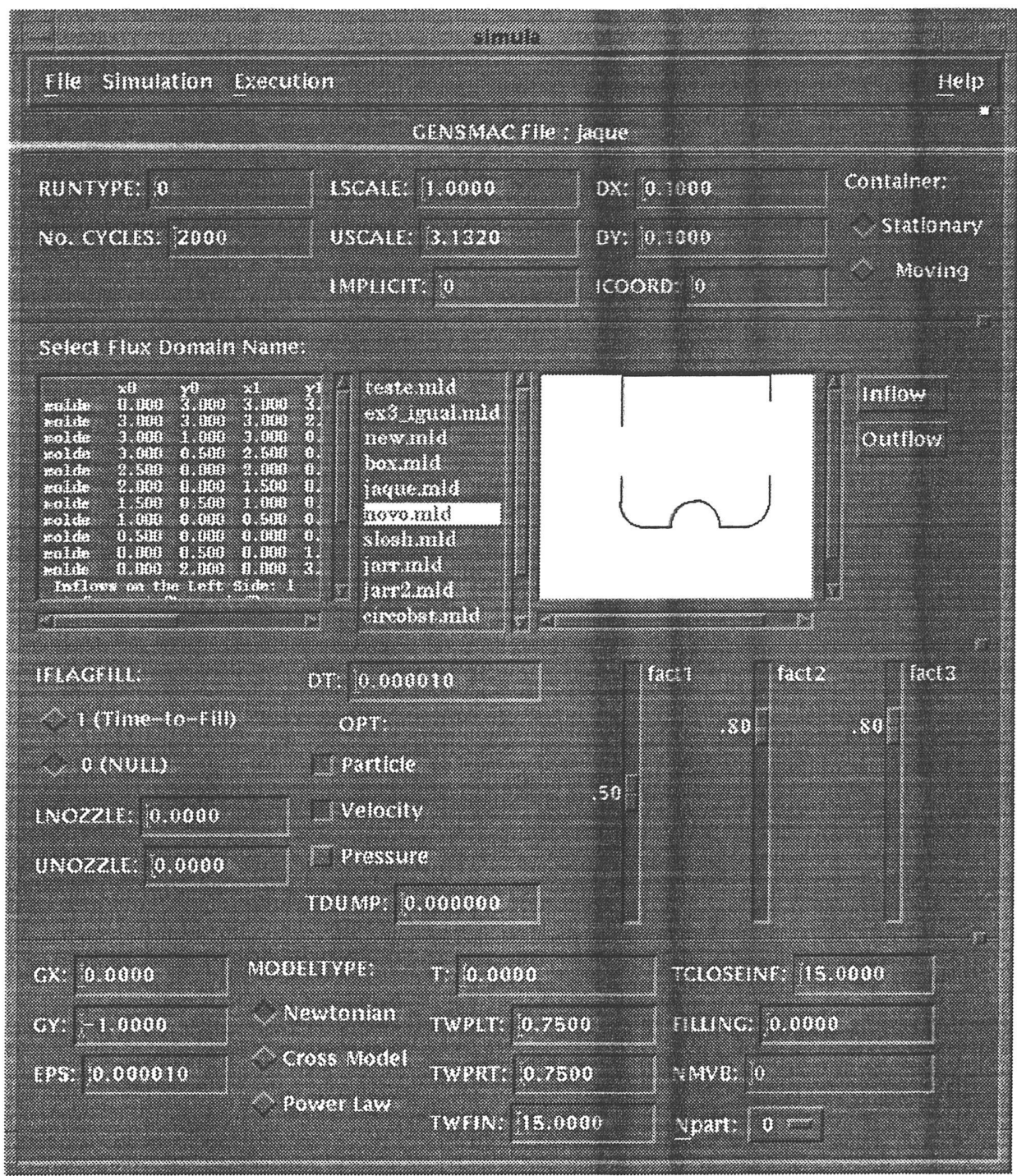

Fig. 5.13: A interface para entrada de dados do Simulador FREEFLOW.

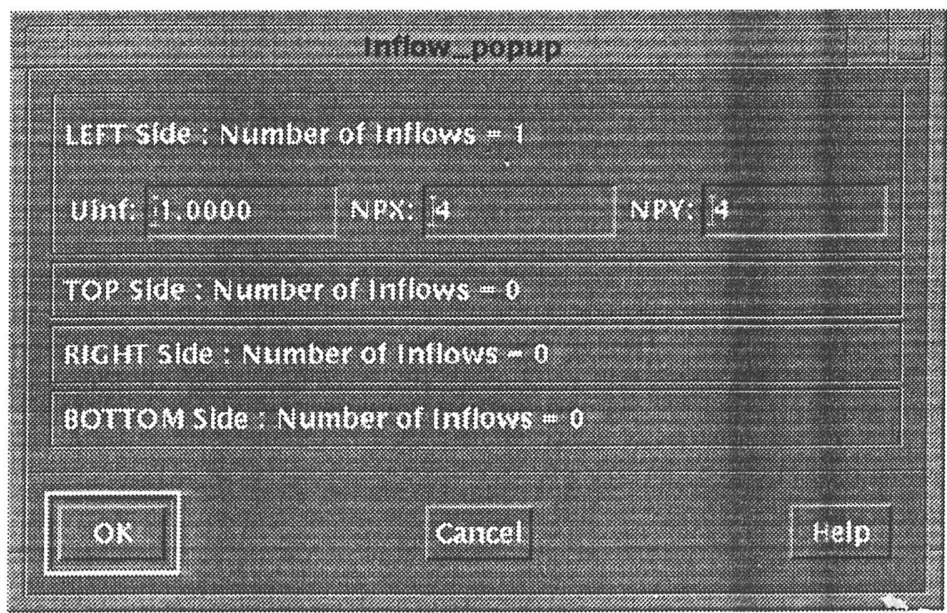

Fig. 5.14: Janela para introdução de informações sobre o inflow do molde selecionado na interface para entrada de dados da simulação. 


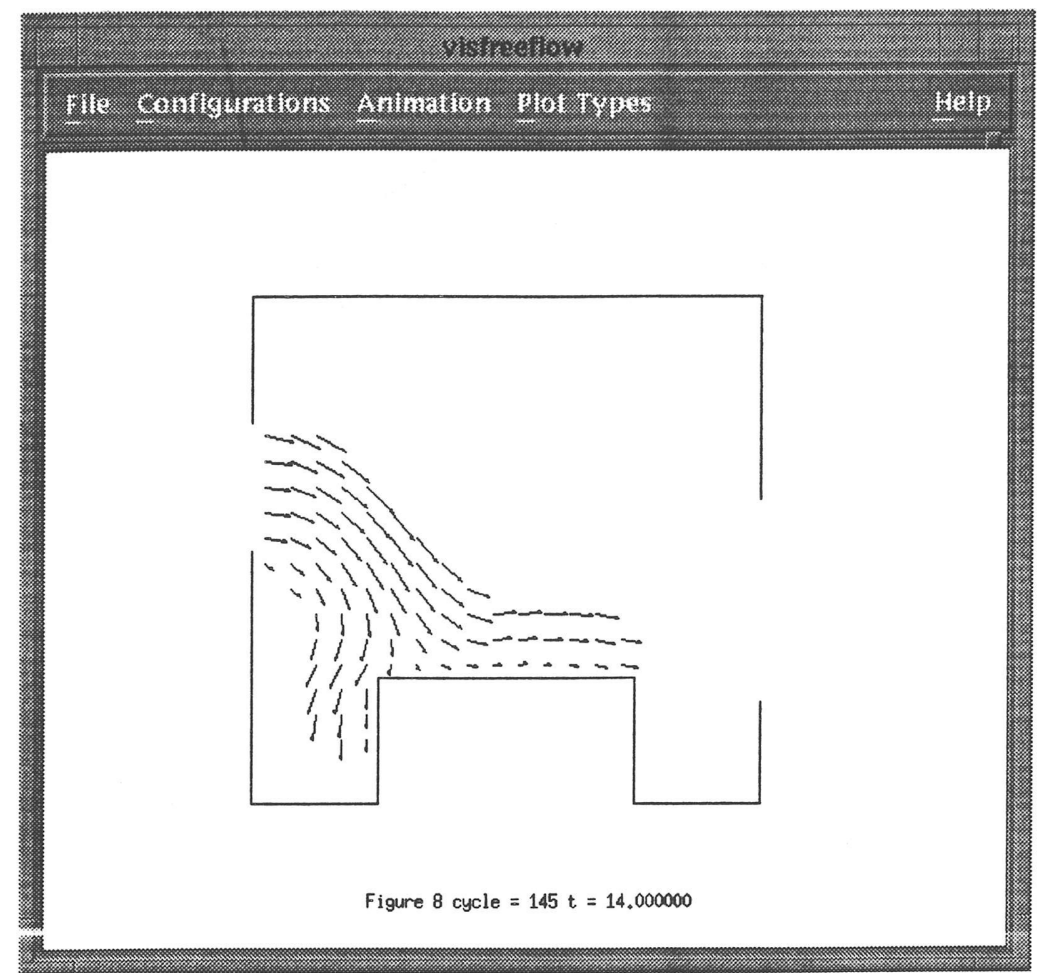

Fig. 5.15: Apresentação de vetores representando a velocidade do fluido.

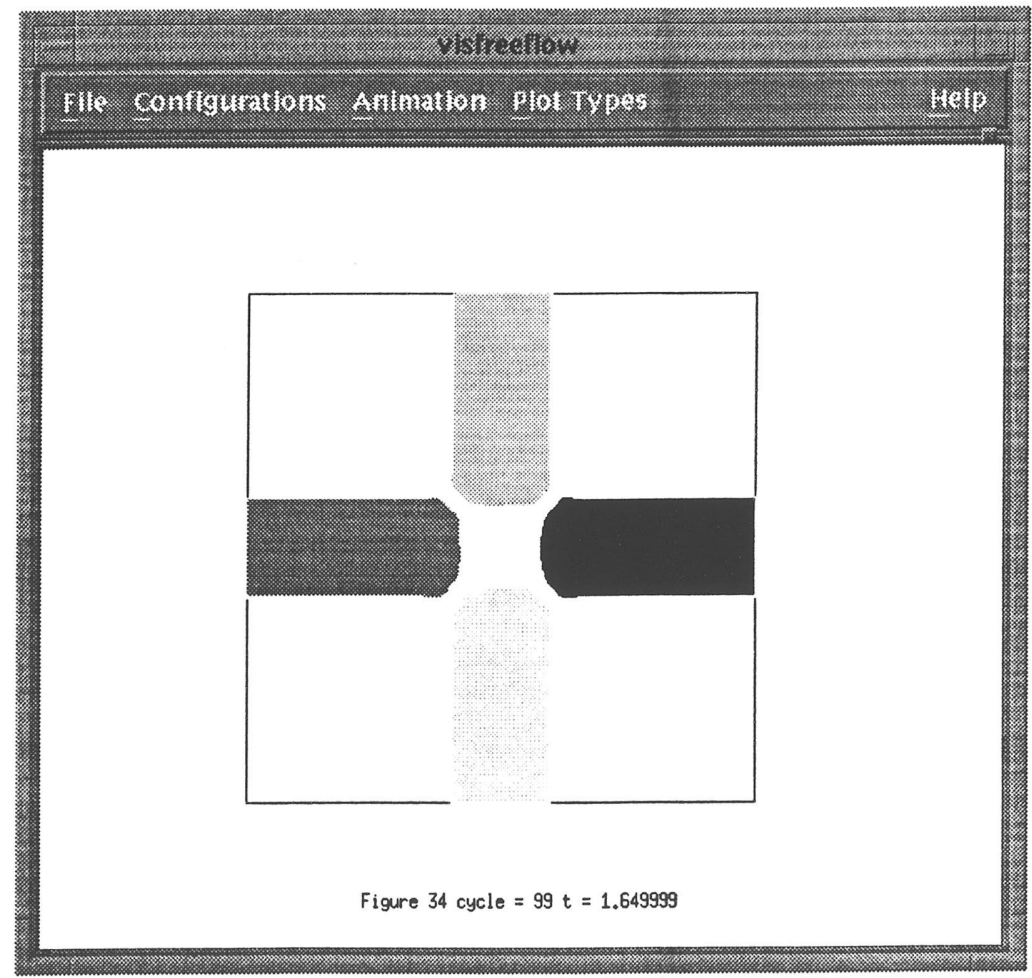

Fig. 5.16: Apresentação do bordo do fluido preenchido com cores distintas. 


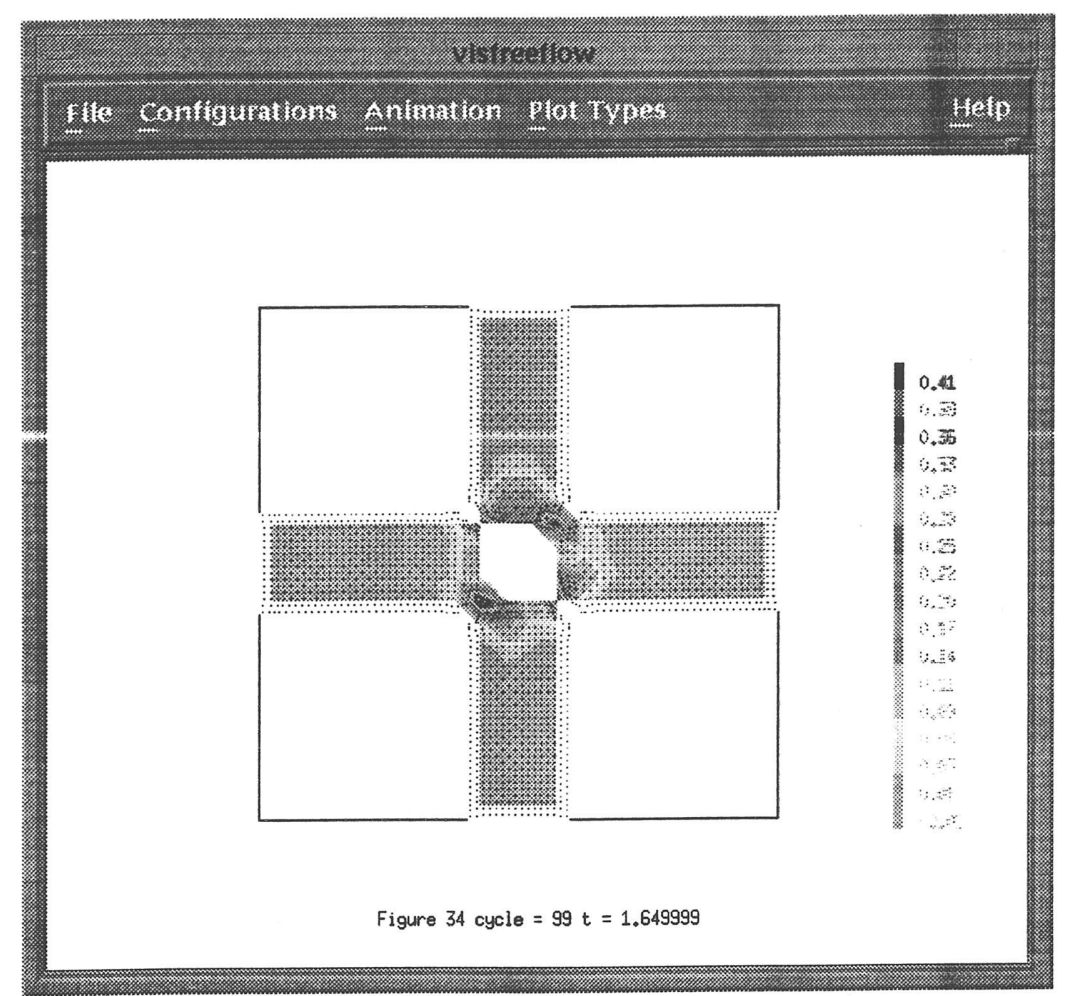

Fig. 5.17: Sobreposição dos campos pressão, mostrado com contornos preenchidos e partículas de fluido.

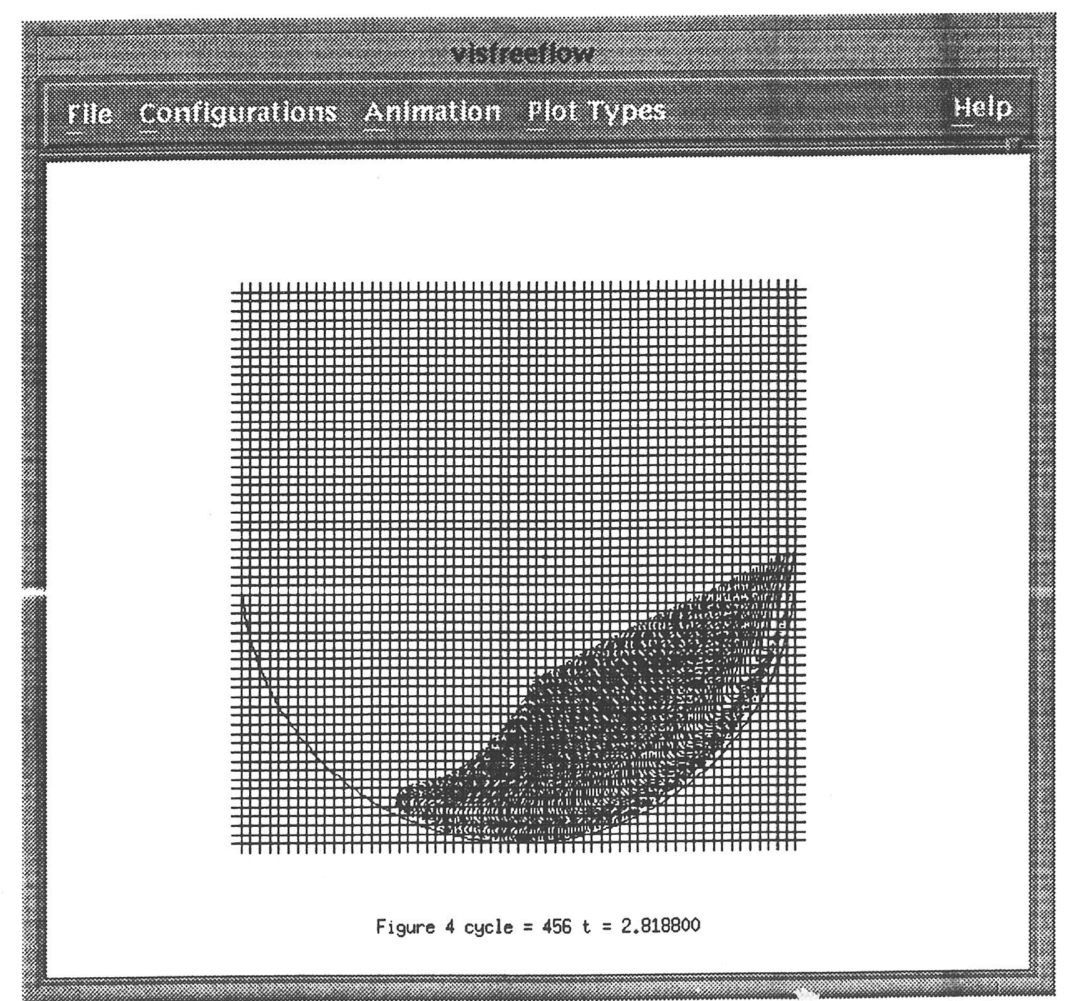

Fig. 5.18: Sobreposição dos campos partículas e grade de células. 


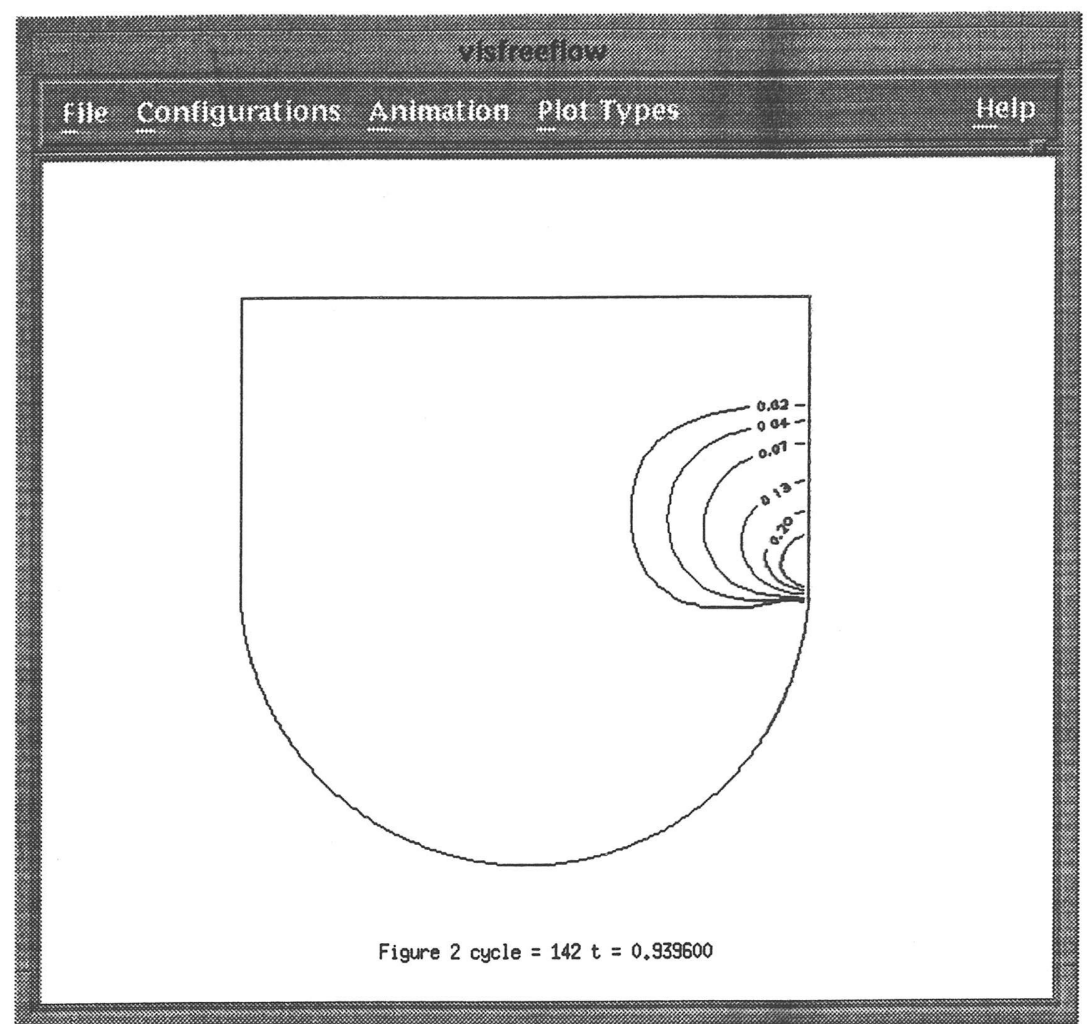

Fig. 5.19: Linhas de contorno escolhidas pelo usuário.

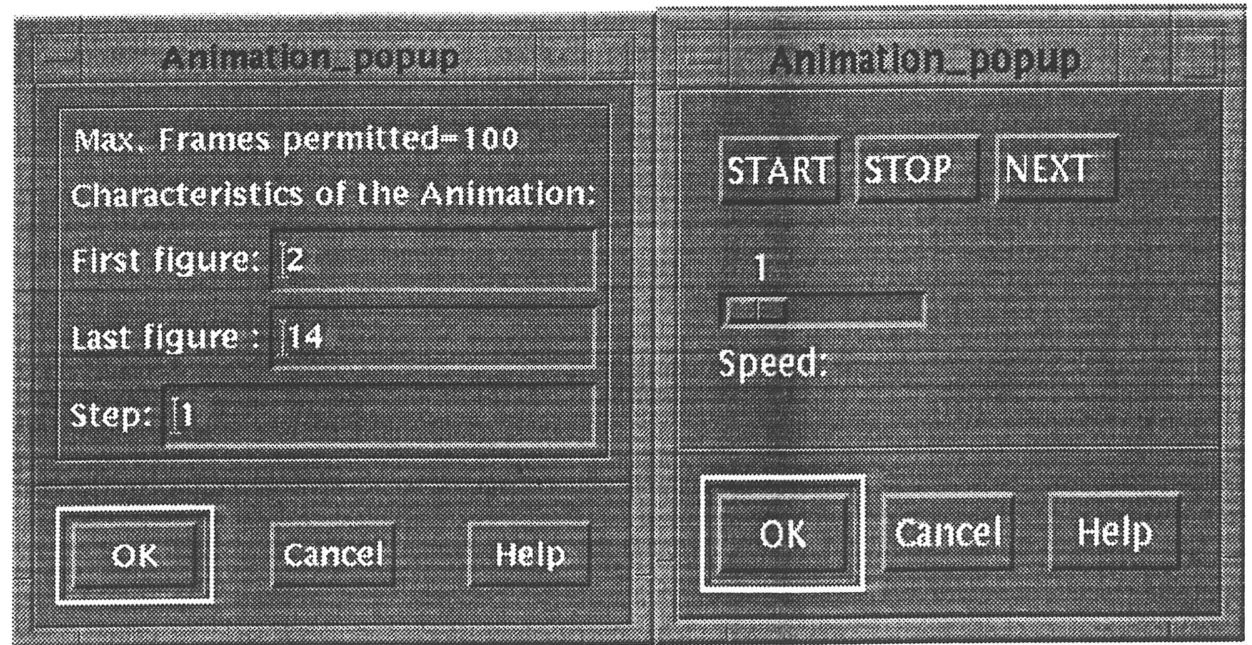

Fig. 5.20: Janelas para controle da animação. 


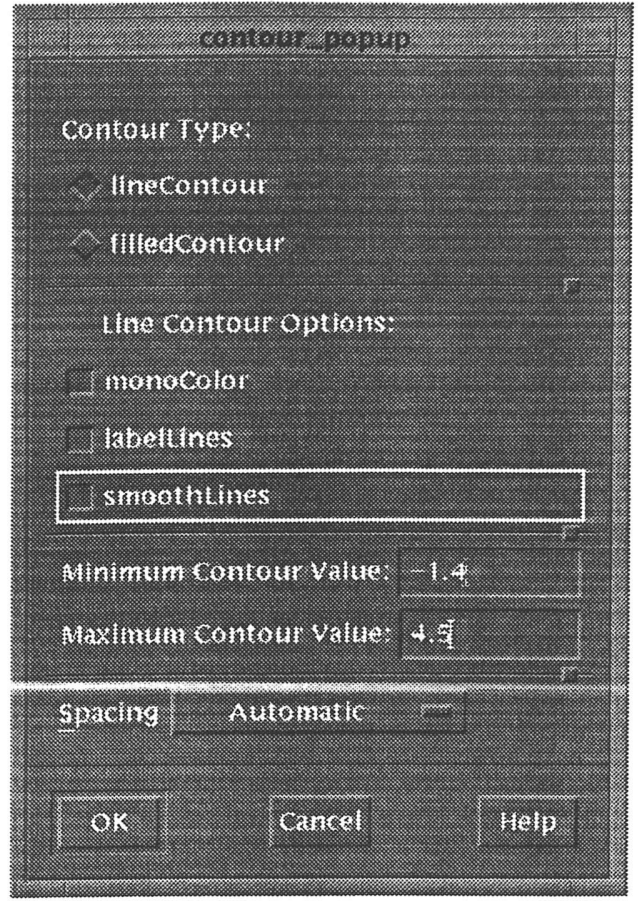

Fig. 5.21: Janela para configurar a apresentação das linhas de contorno.

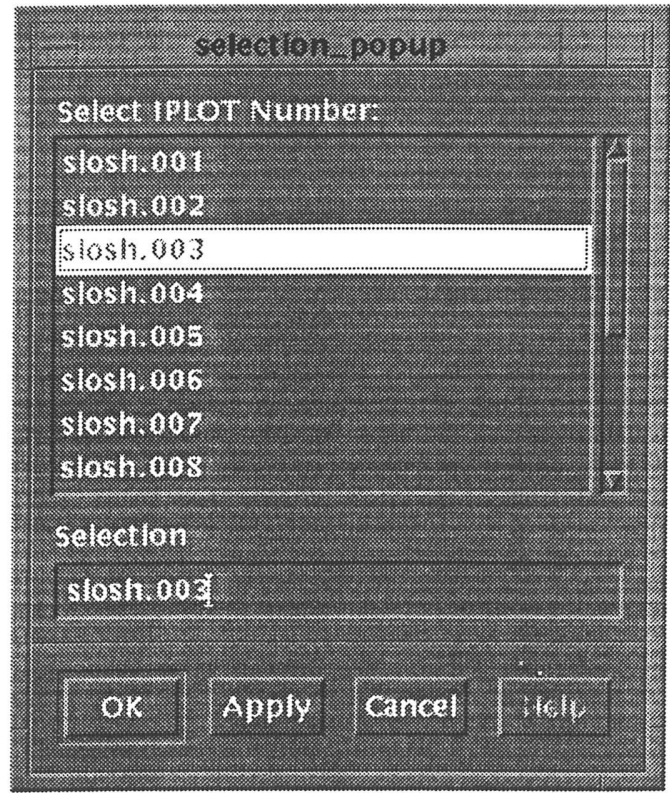

Fig. 5.22: Janela para escolha do passo no tempo ou índice de plotagem (IPLOT). 


\section{Capítulo 6}

\section{Conclusões}

A qualidade de uma interface com o usuário freqüentemente determina a aceitação ou rejeição de um sistema computacional e, conseqüentemente, seu sucesso ou fracasso no mercado de software. Muitas vezes, a interface gráfica é mais importante do que a sofisticação técnica do aplicativo, principalmente nos estágios iniciais de uso.

Dentro deste contexto se enquadra o desenvolvimento deste trabalho, cujo objetivo principal foi prover o Simulador de Escoamento de Fluidos (FREEFLOW), de uma interface gráfica amigável que possibilitasse o seu uso por usuários não especialistas. Este objetivo foi alcançado com a construção do Modelador de Moldes para introdução gráfica de informações sobre o domínio do escoamento, pela implementação da interface para entrada e consistência de dados e monitoramento da simulação e pela possibilidade de realizar visualizações gráficas dos resultados de tais simulações.

Um outro aspecto a ser destacado é a utilização dos módulos desenvolvidos como ferramenta de auxílio ou como base para a construção da interface gráfica do simulador 3D.

O Modelador de Moldes 2D, com suas facilidades de manipulação interativa, pode ser utilizado na construção de sólidos que representam o molde 3D através da técnica de varredura. $\mathrm{O}$ molde $2 \mathrm{D}$ representa a figura plana que descreve uma seção transversal ou um perfil axial do sólido e que, juntamente com a definição de uma trajetória, permite a criação do molde por varredura translacional ou rotacional. O poder descritivo da varredura está relacionado à capacidade de descrição da face planar. É interessante prover o 
modelador 2D de um número maior de primitivas planares, incluindo primitivas fechadas, como quadriláteros, círculos, polígonos, etc, e incluir capacidades de combinações de primitivas através de operações booleanas (união, intersecção e diferença).

As rotinas de visualização do escoamento de fluidos podem ser utilizadas para apresentar a seções verticais ou transversais no volume constituído pelos dados resultantes da simulação 3D.

Este trabalho também propiciou o conhecimento básico de elementos da modelagem geométrica, bem como de aspectos da visualização computacional. Um enfoque mais detalhado foi dado na técnica de construção de modelos através de B-splines e nos métodos para construção de mapas de contornos para visualização de dados na forma de grades.

A construção desses três módulos: modelador de moldes, interface de entrada de dados para o simulador de escoamento de fluidos e visualizador de escoamento de fluidos, proporcionou o aprendizado em programação para o ambiente de janelas $\mathrm{X}$ Window, usando os elementos de interface das bibliotecas X Toolkit Intrinsics e Motif. 


\section{Bibliografia:}

[Bart87] Bartels, B., Beatty, J. \& Barsky, B., "An Introduction to Splines for Use in Computer Graphics and Geometric Design”, Morgan Kaufamann, 1987.

[Burd78] Burden, R., Faires, J.D., Reynolds, A.C, "Numerical Analysis", Weber \& Schimidt Incorporated, Boston, Massachussets.

[Carp84] Carpenter,L., "The A-buffer, an Antialiased Hidden Surface Method", SIGGRAPH 84, 103-108.

[Coon63] Coons, S. A., "An Outline of the Requirements for a Computer Aided Design System". Proc. Spring Joint Comp. Conf., pp. 299, Spartan Books, Baltimore, 1963.

[Cott69] Cottafava,G. e Le Moli, G. (1969): “Automatic Contour Map", Comm. ACM, vol. 12, n.7,p. 386-391

[Cox71] Cox, M. "The Numerical Evaluation of B-splines", DNAC 4, National Physical Laboratory, 1971.

[DeBo72] De Boor, C. “On Calculating with B-splines”, J. Approx. Theory, 6,50-62, 1972. 
[Fari90] Farin, G. "Curves and Surfaces for Computer Aided Geometric Design", Academic Press, 1990.

[Ferg93] Ferguson, P. M. “Motif Reference Manual”O'Reilly \& Associates, Inc.,vol 6b, 1993.

[Fole90] Foley, J. D. et al. "Computer Graphics: Principles and Practice". Addison Wesley Publishing Company, 1990.

[Gome90] Gomes, J. \& Velho, L. C. "Conceitos Básicos de Computação Gráfica”, VII Escola de Computação - IME - USP, 1990.

[Gord74] Gordon, W. \& Riensenfeld, R. "B-spline Curves and Surfaces", R. E. Brnhill and R. F. Riensefeld editors, Computer Aided Geometric Design, pp. 95126, Academic Press, 1974.

[Hall93] Hall,V. "Morphing in 2D and 3D", Dr. Dobb's Journal, v. 18, n.17, julho 1993.

[Harl71] Harlow, F. H. \& Amsden, A. A.”A Simplified MAC Technique for Incompressible Fluid Flow Calculations”, J. Comput. Phys, 8, 197, 1971.

[Hell94] Heller, D, \& Ferguson, P.M, "Motif Programming Manual", O’Reilly \& Associates, Inc, vol 6a, 1994. 
[Hirt69] Hirt, C. W. \& Shannon, J., J. Comput. Phys., 2, 403, 1969.

[Husa94] Husain, K. “Extending Imake”, Dr. Dobb's Journal, June, 1994.

[Maga94] Magalhães, A. L. C. C. “Um Modelador de Sólidos Multirrepresentacional: Estudo, Projeto e Implementação", Dissertação (Mestrado em Ciência da Computação). Instituto de Ciências Matemáticas de São Carlos - USP, 1994.

[Mänt88] Mäntylä, M. “An Introduction to Solid Modeling”. Computer Science Press, 1988.

[Marl76] Marlow,S. e Powell,M.J.D. (1976): "A Fortran Subroutine for Plotting the Part of a Conic that is Inside a Given Triangle", UKAEA Harwell Paper AERE-R 8336. HMSO, London.

[Mort85] Mortenson, M. E. “Geometric Modeling”. John Wiley \& sons, Inc, 1985.

[Nye92] Nye, A. “Xlib Programming Manual” O’Reilly \& Associates, Inc., vol 1, 1992.

[Nye93] Nye, A., O’Reilly, T., “X Toolkit Intrinsics Programming Manual” O’Reilly \& Associates, Inc., vol 4, 1993. 
[Reev81] Reeves, W.T., "Inbetweening for Computer Animation Utilizing Moving Points Constraints", Proceedings of SIGGRAPH'81, vol.15, pp. 263-269, Agosto 1981.

[Requ77] Requicha, A. G. \& Voelcker, H. B. "Constructive Solid Geometry". Production Automation Project, Tech. Memo. No. 25, University of Rochester, 1977.

[Requ80] Requicha, A. G. "Representations of Rigid Solids: Theory, Methods and Systems". ACM Computing Surveys, (12) 4 pp. 437-464, Dezembro 1980.

[Requ83] Requicha, A. G., Voelcker, H. B., "Solid Modeling: Current Status and Research Directions", IEEE Computer Graphics and Applications, Los Alamitos, vol.3, pp. 25-37, outubro, 1983.

[Robe63] Roberts, L. G. "Machine Perception of Three Dimensional Solids". MIT Lincon Laboratory TR315, Massachusetts Institute of Technology, Cambridge, Maio 1963.

[Roge85] Rogers, D. F. "Procedural Elements for Computer Graphics", McGraw-Hill, New York, 1985.

[Roge89] Rogers, D. F. \& Adams, J. S. "Mathematical Elements for Computer Graphics", McGrawHill, 1989. 
[Rose91] Rosenblum, J.L. \& Nielson, G.M. "Visualization Comes of Age", IEEE Computer Graphics and Apllications, maio 1991.

[Roth82] Roth, S. "Ray Casting for Modeling Solids", CGIP, 18(2), fevereiro de 1982.

[Same84] Samet, H., "The Quadtree and Related Hierarchical Data Structures", Computing Surveys, vol.16, n.2, junho, 1984.

[Samt94] Samtaney, R., Siver, D., Zabursky, N., Cao, J. "Visualizing Features and Tracking Their Evolution", IEEE Computer, julho 1994.

[Scho46] Schoenberg, I. J. "Contributions to the Problem of Approximation of Equidistant Data by Analytic Functions", Quart. Appl, Math, 4, 45-99, 1946.

[Sibs81] Sibson,R. e Thomson,G.D. (1981): “A Seamed Quadratic Element for Contouring", The Computer Journal,vol.24,no.4,pp.378-382

[Suff84] Suffern, K. G. "Contouring Functions of Two Variables", The Australian Computer Journal, vol.16, no. 3, pp. 102-106.

[Suff90] Suffern, K. G., "Quadtree Algorithms for Contouring Functions of Two Variables", The Computer Journal, vol. 33, no.5, pp. 402-407 
[Suth63] Sutherland, I. E. "Sketchpad: A Man-Machine Graphical Communication System". Proc. Spring Joint Comp. Conf., pp. 329, Spartan Books, Baltimore, 1963.

[Suth74] Sutherland, I. E., Sproull, R.F., Schumacker, R.A. "A Characterization of Ten Hidden Surface Algorithms", ACM Computing Survey,6(1),março 1974

[Tome91] Tome, M \& McKee, S. “GENSMAC", Department of Mathematics Research Report 25, University of Strathcycle, 1991.

[Tome94] Tome, M \& McKee, S. "GENSMAC: A Computational Marker and Cell Method for Free Surface Flows in General Domain", Journal of Computational Physics,vol.110, no. 1, Janeiro, 1994.

[Tome96a] Tome, M., Castelo Fo., A., Murakami, J., Cuminato, J. A. “A Marker-andCell Technique for Solving Axysimmetric Free Surface Flows", submetido e aceito nos anais do VI ENCIT (Congresso Brasileiro de Engenharia e Ciências Térmicas).

[Tome96b] Tome, M, Castelo Fo.,A, Cuminato, J.A., McKee, S. "GENSMAC3D: Implementation of the Navier Stokes Equations and Boundary Conditions for 3D Free Surface Flows. 
[Warn69] Warnock,J. "A Hidden-Surface Algorithm for Computer Generated HalfTone Pictures", tec. report TR 4-15, NTIS AS-753 671, Univ. Utah, junho 1969.

[Watk70] Watkins, G.S. "A Real Time Visible Surface Algorithm", Ph.D Thesis, Tec. report UTEC-CSs-70-101,NTIS AD-762 004, Univ. of Utah, junho 70. 